NBER WORKING PAPER SERIES

PRODUCTION, SALES, AND THE CHANGE IN INVENTORIES:

AN IDENTITY THAT DOESN'T ADD UP

Jeffrey A. Miron

Stephen P. Zeldes

Working Paper No. 2765

NATIONAL BUREAU OF ECONOMIC RESEARCH

1050 Massachusetts Avenue

Cambridge, MA 02138

November 1988

We are grateful to Joe Beaulieu, Edward Gold and Amy Lipton for research assistance. We thank Joe Altonji, Larry Christiano, Frank de Leeuw, Jim Kahn, Zoltan Kenessey, Craig Mackinlay, Richard Raddock, Christina Romer, David Romer, Ruth Runyon, Chris Sims, David Wilcox, a referee, members of the Penn Macro Lunch Group and workshop participants at Brown, Harvard, Michigan, UT Austin, and the Federal Reserve Board for helpful comments and discussions. Support from the Olin Foundation is acknowledged. This research is part of NBER's research program in Economic Fluctuations. Any opinions expressed are those of the authors not those of the National Bureau of Economic Research. 


\section{PRODUCTION, SALES, AND THE CHANGE IN INVENTORIES: \\ AN IDENTITY THAT DOESN'T ADD UP}

\section{ABSTRACT}

We examine two measures of monthly manufacturing production. The first is the index of industrial production; the second is constructed from the accounting identity that output equals sales plus the change in inventories. We show that the means, variances, and serial correlation coefficients of the $\log$ growth rates differ substantially between the two series, and the cross-correlations between the two seasonally adjusted series are in most cases less than .4. A model of classical measurement error indicates that in 15 of 202 -digit industries measurement error accounts for over $35 \%$ of the variation in the monthly growth rates of seasonally adjusted industrial production.

Jeffrey A. Miron

NBER

1050 Massachusetts Avenue

Cambridge, MA 02138
Stephen P. Zeldes

NBER

1050 Massachusetts Avenue

Cambridge, MA 02138 


\section{Introduction}

In this paper we examine two measures of monthly production that have been used by economists. The first measure, which we refer to as IP, is the index of industrial production constructed by the Board of Governors of the Federal Reserve. This measure is used extensively in empirical work on the business cycle, as well as by policymakers and others to assess the current state of the economy. The second measure, which we refer to as $\mathrm{Y}_{4}$, is constructed from the accounting identity that output equals sales plus the change in inventories. Sales and inventory data are reported by the Department of Commerce. This measure of output is frequently used to estimate models of inventory accumulation. Theoretically, these two series measure the same underlying economic variable -- the production of goods by manufacturing firms during the month.

We show here that the time series properties of these two series are radically different. We examine means, variances, and serial correlation coefficients of the $\log$ growth rates and show that these statistics differ substantially between the two series. Generally, IP is a less volatile and more persistent series than is $\mathrm{Y} 4$. In addition, the cross-correlations between the two seasonally adjusted series range from .6 to .0 and are in most cases less than $.4 .^{1}$ We then demonstrate the significance of these differences in two ways. First, we show that the variance bounds results of Blinder's (1986) study of inventory behavior are partially reversed when the IP rather than the $\mathrm{Y} 4$ output measure is used. Second, we examine two specific models of the measurement error in the series. The estimates under one of them (classical measurement error) indicate that in 15 out of 202 -digit industries measurement error accounts for over $35 \%$ of the

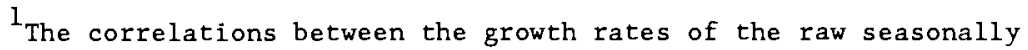
unadjusted series are always higher, ranging from .4 to .9. 
variation in the monthly growth rates of seasonally adjusted industrial production data.

These results are important for all those who use the IP or Y4 data. This includes particularly researchers on inventories, since some studies use the IP measure while others use the Y4 measure. ${ }^{2}$ More generally, many studies of the business cycle employ IP as a measure of economic activity. Our results supplement the work of Lichtenberg and Griliches (1986) who show that substantial measurement error exists in industry level price indexes.

The remainder of the paper is organized as follows. Section II describes how the two data series are constructed. Section III presents summary statistics that demonstrate the differences between the two series, and section IV gives an example of the economic significance of the discrepancies. In section $V$ we model the measurement error and estimate its importance under alternative sets of assumptions. Section VI concludes the paper.

\section{Data Construction}

In this section we describe how the data released by the relevant government agencies are constructed, and how we use these data to construct Y4.

\section{A. Construction of IP}

The Federal Reserve Board's (FRB) index of industrial production is available monthly, both seasonally adjusted (SA) and seasonally unadjusted

${ }^{2}$ B1inder (1986) and West (1986) use the Y4 measure, while Maccini and Rossana (1984) and Reagan and Sheehan (1985) use the IP measure. Miron and Zeldes (1988) report two sets of results: one using IP and the other using Y4. West points out in his footnote 13 that he estimated his equations for a few of the industries using the IP measure as well. He found that the parameters were uniformly non-sensical and therefore did not report them. 
(NSA), at the 2-digit level, from 1959 to the present. The series are published in the Survey of Current Business and the Federal Reserve Bulletin. The 2-digit series and the more aggregated series are constructed from disaggregated data using value-added weights.

The disaggregated IP indexes are constructed from three types of data: physical product measures, kilowatt-hours of electrical power input, and man-hours of labor input. Each of these is collected at either the establishment (plant) level or at the more specific product level. The input measures are used in cases where the physical product numbers are not available or would not make sense because of heterogeneity in the product. For the physical product measures, the FRB uses series from the Department of Energy, the Bureau of the Census and other public and private sources. Most of these are counts of output goods, although occasionally (e.g., steel) they are constructed as the sum of sales and inventory changes. ${ }^{3}$ For the kilowatt-hour data, the FRB asks utility companies their sales of kilowatt hours of electric power to firms in manufacturing. ${ }^{2,5}$ For the man-hours series, the Bureau of Labor Statistics provides data from its

${ }^{3}$ The physical product numbers are divided by the number of working days in the reporting period in order to put each series on a per-workingday basis.

${ }^{4}$ Unfortunately, the reports do not measure electricity use on a calendar month basis, because billing dates fall throughout the month and thus cover different month long periods for different customers (Federal Reserve Board, 1986, p. 42).

5 Monthly movements in the data are reviewed to eliminate "abrupt movements that cannot be accounted for by such developments as work stoppages, power shortages, or cyclical movements," and are presumed due to inappropriate reports (FRB, 1986, p.42).

${ }^{6}$ The FRB also asks "self-generators" of electricity in the manufacturing industry to report power used in manufacturing. 
at the 2-digit level. We adjust the finished goods and work in progress inventory series from cost to market by multiplying each by an industryspecific constant, as described in West (1983) and Holtz-Eakin and Blinder (1983), respectively.

To arrive at the constant dollar inventory series, the BEA begins with data on the book value of inventories collected by the Bureau of the Census at the Commerce Department and adjusts these for differences between book and current dollar values and also for differences between current and constant dollar values. This complicated procedure incorporates information about whether firms use LIFO or non-LIFO accounting methods and involves estimating the accounting age structure of the existing stock of goods. The conversion procedures are described in detail in Hinrichs and Eckman (1981) and in Foss, et al. (1980). ${ }^{12}$

The book value data are collected by the Census through three surveys: the monthly M3 (Manufacturers' Shipments, Inventories, and Orders), the

12 The book value data measure the value of the goods currently in inventory, at acquisition cost. For example, when prices are rising over time, an item in inventory that is three years "old" in accounting terms will have a lower book value than an identical item that is one year "old," because it is on the books as having been acquired in different years at different costs. The accounting age of goods in inventory very much depends on the method of inventory accounting used.

When a firm uses LIFO accounting, positive changes in book value inventory levels accurately measure current dollar increases. These changes are deflated into constant dollars, and then cumulated to get a constant dollar stock. Negative changes in book value numbers imply that goods from previous LIFO layers were sold, and an estimate must be made of the acquisition date and cost.

When a firm uses non-LIFO accounting, the procedure is more complicated. Even if the number of goods in inventory does not change in a month, the book value of inventories may still change, because "old" lower cost inventories were replaced on the books with "new" higher cost inventories (again assuming prices are rising). The BEA must estimate the entire age structure of inventories (based on turnover ratios), and then the book value of the goods of each age must be divided by an estimate of the acquisition cost of the goods of that age. See Foss, et al (1980, pp. 47-49). 
Annual Survey of Manufactures, and the quinquennial Census of Manufactures. The $M 3$ is a voluntary survey of large companies. There are a total of only 4500 reporting units, made up of 3400 companies and 1100 divisions of 450 companies. Reporting units often produce more than one type of good, and sometimes these goods fall into different industry classifications. In this case, all of the inventories and shipments of the reporting unit are lumped into the primary industry classification. Units report total book value inventories, and then a breakdown into three stages of fabrication: materials and supplies, goods in process, and finished goods. ${ }^{13}$ on each monthly survey, units are given the opportunity to revise the previous two months' information.

The BEA reports only SA data, and therefore the above procedure gives seasonally adjusted Y4. We create NSA shipments and inventories data using the procedures in Reagan and Sheehan (1985), West (1986), and Miron and Zeldes (1988). For both the level of shipments and the level of inventories, the technique is to multiply the real seasonally adjusted series produced by the BEA by a seasonal factor, equal to the ratio of the seasonally unadjusted to the seasonally adjusted nominal (shipments) or book value (inventories) data. This procedure is appropriate as long as there is relatively little seasonality in prices or in the factors used to convert from book to nominal. 14 In Table Bl, we present information on the seasonality of the $\log$ growth rate of the producer price index in seventeen

${ }^{13}$ The reliability of the stage of fabrication data is lower than for the totals: some firms group work in process inventories in with either materials or finished goods, and others double count because one stage in a reporting unit may overlap another stage in another reporting unit for the same firm (Foss, et al. (1980), p. 21).

${ }^{14}$ The book/nominal distinction is only relevant for inventories (not for shipments). 
of the twenty 2 -digit industries examined here. ${ }^{15}$ The message conveyed is that there is statistically significant seasonality in prices in most of the industries considered here, but this seasonality is sufficiently small relative to the seasonality in output that it is probably not an important factor in the re-seasonalization of the data.

\section{The Time Series Properties of the Two Measures of Production}

The description of the construction of the two series makes it clear that they are unlikely to be numerically identical. In this section, we quantify the extent to which the series diverge and show that the differences are significant.

The analysis is carried out for all twenty 2-digit manufacturing industries, as well as for three aggregates of these industries (durables, non-durables, and total). ${ }^{16}$ we consider first the seasonally adjusted data, since these are the ones most familiar to a majority of readers. We also present results for seasonally unadjusted data, however, and we examine the seasonal movements themselves. With the exception of the variance bounds tests, the results presented below all focus on the

${ }^{15}$ The prices used do not correspond exactly to the SIC classification for output, although the correspondence is close. The first two columns report results of tests of the hypothesis of no seasonality, while the third column reports the standard deviation of the estimated seasonal coefficients. To calculate the test statistics, we regressed the log growth rate of prices on a constant and eleven seasonal dumies and tested the hypothesis that the dummies were jointly zero (where the variancecovariance matrix was computed using the Newey and West (1987) procedure.) To calculate the standard deviation of the seasonal coefficients, we regressed the $\log$ growth rate on twelve seasonal dumies and took the standard deviation of the coefficients. In the fourth and fifth columns we present the standard deviation in the estimated seasonal coefficients in the $\log$ growth rates of IP and $\mathrm{Y} 4$, along with the ratio of these standard deviations to those in prices.

${ }^{16}$ Plots of the $\log$ levels of the two series (with the levels in 1967.01 set equal) for a selected group of industries are included in Appendix B. 
logarithmic growth rates of the relevant series. We employ growth rates because the resulting series are likely to be stationary whether the secular growth is generated by a unit root or by a deterministic time trend. In the Appendix (Table B2), we present results of Dickey Fuller tests of the hypothesis of no unit root in the autoregressive representation of these series. In almost all of the 2-digit industries, we do not reject the null hypothesis of a unit root at the 95 level of significance.

\section{A. Descriptive Statistics}

Table 2 a presents the means, standard deviations, and first order autocorrelation coefficients of the $\log$ growth rates of the monthly seasonally adjusted IP and Y 4 series, as well as tests of the hypotheses that these statistics are equal for IP and Y4. ${ }^{17}$ The sample period is May 1967 through December 1984. ${ }^{18}$

17 We compute these test statistics as follows. For the means, we regress the difference between the $\log$ growth rates of IP and Y4 on a constant and test the hypothesis that the constant term is zero. For the variances, we regress the log growth rate of IP on the difference between the $\log$ growth rates of IP and $\mathrm{Y} 4$ and test the hypothesis that the coefficient on the difference in growth rates is equal to .5. For the autocorrelations, we stack the IP and Y4 observations and regress the growth rate of output on the lagged growth rate, a dumny that is 1 for the IP observations and 0 for the $Y_{4}$ observations, and this dummy multiplied by the lagged growth rate. The test statistic is the t-statistic on this last variable. For the seasonal patterns, we regress the difference in log growth rates on a constant and eleven seasonal dummies and test the hypothesis that the coefficients on the eleven dummies are jointly equal to zero.

In a1l of these tests, we use the Hansen and Hodrick (1980) / Newey and West (1987) procedure to estimate the standard errors (with the lag length set to 12 and the damping factor set to 1.0). These test procedures therefore allow for general serial correlation and/or heteroskedasticity in the $\log$ growth rates of IP and Y4.

${ }^{18}$ We use only post-1967 data because there were changes in the definitions of the SIC codes in 1967 that make the pre-1967 data not completely compatible with post-1967 data. 
The results in the table indicate that the time series properties of IP and Y4 are substantially different. Consider first the cross correlations between the growth rates of the two different measures of production. These correlations range from a low of -.02 for Printing to a high of .64 for Primary Metals. Eighteen of the twenty-three correlations reported are less than $.4 .^{19,20}$ The correlations are higher for the aggregates than for the individual series.

Examination of the first order autocorrelations reveals the surprising result that in 13 out of 23 cases, the autocorrelation is positive for IP but negative for Y4. For example, for non-durables as a whole, the first order serial correlation of growth rates equals . 30 for IP and -.25 for $\mathrm{Y} 4$. The difference in the autocorrelation coefficients is statistically significant in 17 of 23 cases. These differences are generally not eliminated over longer horizons; we find that the sum of the first 24 autocorrelations is almost always higher for IP than for Y4. ${ }^{21}$ Thus the IP measure exhibits significantly more persistence than does Y4.

${ }^{19}$ Harrison and Stewart (1986) report similar results for the two corresponding Canadian data series. They report correlation coefficients between the detrended seasonally adjusted levels (rather than growth rates) as low as .56 , with the majority of industries between .7 and .8 .

Sims (1974, p. 704), using U.S. manufacturing data, finds that labor input is estimated as a one sided distributed lag of IP but a two sided distributed lag of the BEA's measure of shipments or shipments plus the change in finished goods inventories (see Sims' footnote 20). Sims interprets this as evidence that shipments (as a proxy for output), or shipments plus the change in inventories, may be measured with greater error than IP.

${ }^{20}$ The correlations between IP and shipments (unadjusted for inventory changes) are actually greater than those between IP and Y4 in 14 of 20 industries in the SA data (10 of 20 in the NSA data).

${ }^{21}$ Campbell and Mankiw (1988) explain why the sum of the autocorrelations is a useful, non-parametric measure of persistence. 
Turning to the standard deviations, the results indicate that the IP measure is much less volatile than the $\mathrm{Y} 4$ measure. In all cases the standard deviation is higher for the Y4 measure than for the IP measure, and in 12 of the industries the point estimates indicate it is more than twice as large. The differences are statistically significant in all but one case. Finally, in a few cases the mean growth rate is twice as high for one measure as for the other. The differences in means, however, are in most cases not statistically significant. 22

In Table $2 b$ we present summary statistics and hypothesis tests for the seasonally unadjusted data. The correlations between the two series are in every case higher than with adjusted data, reflecting the comovements due to seasonality, but the correlations are nevertheless well below one in most cases. For 9 of the 23 series, the sign of the first order autocorrelation coefficient is positive for one series and negative for the other series. The difference in the autocorrelation coefficient is statistically significant in 13 of 23 cases. The standard deviations of the two series are in all but two cases statistically different.

Figures 1-23 plot the seasonal movements in the log growth rates of the two measures of production. ${ }^{23}$ In most of the industries, the two seasonal patterns are similar with respect to the timing of the peaks and troughs. In several industries, however, the timing of the seasonal

${ }^{22}$ Dickey-Fuller tests on the difference in the logs of the two series indicate that in almost all cases we cannot reject the hypothesis of a unit root in this difference. The fact that the difference between the log levels of the two series is positively autocorrelated explains why we cannot usually reject the hypothesis that the growth rates are the same even though plots of the log levels in some cases diverge substantially over time.

${ }^{23}$ The overall mean growth rate has been subtracted from each seasonal dumny coefficient so that the plotted coefficients have mean zero. 
patterns is similar but the magnitude of the peaks and/or troughs is substantially greater for Y4 than for IP. Hypothesis tests indicate that the seasonal coefficients are statistically different in all 23 cases.

Tables $\mathrm{B} 3 \mathrm{a}$ and $\mathrm{B} 3 \mathrm{~B}$ in the Appendix present results analogous to those in Table $2 a$ for growth rates of quarterly and annual averages of monthly data, respectively. The cross correlations of the quarterly growth rates are higher than those of the monthly data, but still less than .7 in half of the industries. The correlations of annual growth rates are significantly higher, being greater than .9 in 15 out of 20 industries. The generally high correlations of the annual growth rates is consistent with the fact that the information in the Annual Survey of Manufactures and the quinquennial Census of Manufactures is in most cases used to benchmark both IP and Y4.

The evidence presented above demonstrates that there are dramatic differences between the time series properties of the IP and Y4 measures of production. The standard deviations and autocorrelations of the two series differ systematically, and the cross correlations between the two series indicate that there is remarkably little variation that is common to both series. We have discussed the differences with researchers at the $B E A$ and FRB, and, while they are aware of the problem and of numerous differences in the construction of the data, they are not able to offer a definitive explanation. 24,25

24 We presented an earlier version of this paper at the seminar at the Federal Reserve Board, and are appreciative of helpful discussions with Zoltan Kenessey (head of the section that produces the industrial production series), Richard Raddock, Dixon Tranum, and others at the FRB, as well as with Frank de Leeuw and Robert Parker of the BEA.

${ }^{25}$ One possible source of discrepancy is that the FRB uses value added weights to aggregate the individual series, while the BEA, by adding constant dollar series, effectively uses gross value weights. As a check 


\section{The Variance of Production and the Variance of Sales}

In this section we underscore, by way of an example, the economic importance of the discrepancy between the two measures of production. We show that the results of Blinder's (1986) widely cited study of firms' inventory behavior are at least partially sensitive to the choice of output measure. Blinder (1986) emphasizes that, in the absence of cost shocks, the production smoothing model implies that the variance of production should be less than the variance of sales (shipments). ${ }^{26}$ Using the $Y 4$ measure of output, Blinder shows that the variance of production is greater than the variance of shipments for all but one of the industries examined, and he interprets this as strong evidence against the production smoothing model.

In Table 3 we present the ratio of the variance of output to the variance of shipments based on each of the two output measures. The sample period, inventory definition, and detrending techniques were all chosen to correspond as closely as possible to Blinder (1986). Thus, unlike the data in the previous tables, these data are levels (not growth rates), detrended with an exponential trend, and cover the period 1959:2 to 1981:7.27 We

against this possibility, we examine an alternate IP series calculated by the FRB using gross value weights (this was available for seasonally adjusted total manufacturing only, beginning in 1972). Over the period $72: 3$ to $84: 12$, we find that the correlation of growth rates between this series and the standard IP is equal to .83 . The correlation between this series and $\mathrm{Y} 4$ is equal to .59, compared to a correlation of the standard IP and $\mathrm{Y} 4$ of .65 over the same time period. Thus, the use of value added weights does not appear to be a quantitatively important source of the difference between IP and Y4.

${ }^{26}$ If cost shocks are present, then this inequality need not hold (Eichenbaum (1984), Blinder (1986)). Kahn (1987) argues that if production for the period must be chosen before sales are known and if stockouts are possible then this inequality can be violated even in the absence of cost shocks.

27 Blinder's estimation procedure is the following. For both shipments and $\mathrm{Y} 4$, the log level is regressed on a constant, time, a dumny variable that is one beginning in October 1973, and a dummy that is one beginning in 
convert the IP measure from an index into a constant dollar figure by multiplying it by the ratio of average $\mathrm{Y} 4$ to average IP (in other words, we set the average of the two series equal to each other). 28

The results for the $\mathrm{Y} 4$ measure match $B 1$ inder's results almost exactly. ${ }^{29}$ For all but one industry, the variance of output is greater than the variance of shipments. The results for the IP measure, however, are quite different. The variance ratio is in most cases less than the one based on $\mathrm{Y} 4$, and for 11 industries the variance inequality is actually reversed. ${ }^{30}$ It is especially noteworthy that reversals occur in five of the six industries identified by Belsley (1969) as production to stock; these are the industries for which the production smoothing model is the most plausible theoretically. ${ }^{31}$ Had Blinder originally chosen to use IP

1967 in order to account for a data revision that begins in January 1967. (Blinder's paper states that his dummy begins in January 1966, but in private conversation he has informed us that his dummy begins in January 1967.) The coefficients are estimated by GLS, assuming a second order autoregressive process for the error term. The antilogs of the fitted values of this regression are then subtracted from the actual data, in levels, to define the detrended data.

28 Because the ratio of average $Y 4$ to average IP is different for different averaging periods, the choice of base period for conversion of IP sometimes affects the resulting variance bounds ratio for a few industries. Results for different base periods consistently show, however, that the variance ratio using IP data is less than the ratio using $Y 4$ data in a significant number of cases.

${ }^{29}$ The minor differences between the Y4 results in our Table 3 and Blinder's Table I are probably due to data revisions that were released subsequent to Blinder's work but incorporated in our data.

${ }^{30}$ This reversal of the variance bounds inequality was first pointed out by West (1986, footnote 13).

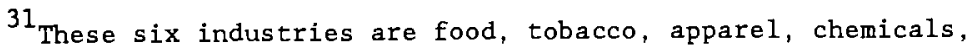
petroleum, and rubber. 
instead of $\mathrm{Y} 4$, he would have reached substantially different conclusions about the empirical validity of the production smoothing model. ${ }^{32}$

\section{The Sources and Importance of Measurement Error}

The fact that IP and $\mathrm{Y} 4$ differ means that at least one of them is measured with error. Up until this point, none of our results has required making assumptions about the types of measurement error present in the data. In this section, we model the measurement error in the series. We begin with a general model and then gauge the importance of different types of measurement error in each series under alternative assumptions about the type of measurement error present. We also attempt (only partially successfully) to determine which types of measurement error are most likely to be present.

We consider two types of measurement error, as in Mankiw, Runkle, and Shapiro (1984) and Mankiw and Shapiro (1986). The first type (classical measurement error) is uncorrelated with the true underlying series. The second type is correlated with the true series, but uncorrelated with the observed series. This second type of measurement error could arise for two reasons. If the announced series are rational forecasts of the underlying series, then the measurement error will be a rational expectations forecast error and thus uncorrelated with the forecast itself. In addition, if there are productivity changes (true productivity shocks or, e.g., changes in productivity due to labor hoarding) that are not captured by the measured series, then the measurement error will include the productivity

32 While this may be interpreted as support for the production smoothing model, Miron and Zeldes (1988) present additional tests and find that a generalized production smoothing model is rejected for both the Y4 data and the IP data (although the rejections are not as strong based on IP data). 
change, which will be correlated with the true output but may be uncorrelated with the measured figures.

We consider the following model:

$$
y_{t}^{I P}+u_{t}^{I P}=y_{t}^{*}+e_{t}^{I P} \quad y_{t}^{Y_{4}}+u_{t}^{Y_{4}}=y_{t}^{*}+e_{t}^{Y_{4}}
$$

where $y_{t}^{*}$ is the $\log$ of the true series; $y_{t}^{I P}$ and $y_{t}^{Y_{4}}$ are the logs of the two measured series; $e_{t}^{I P}$ and $e_{t}^{Y_{4}}$ are measurement errors that are uncorrelated with $y_{t}^{*}$, and $u_{t}^{I P}$ and $u_{t}^{Y 4}$ are measurement errors that are uncorrelated with $y_{t}^{I P}$ and $y_{t}^{Y_{4}}$, respectively. The errors $e_{t}^{I P}, e_{t}^{Y_{4}}, u_{t}^{I P}$, and $u_{t}^{Y_{4}}$ are assumed to be mutually orthogonal. The model in first differences is:

$$
\Delta y_{t}^{I P}+\Delta u_{t}^{I P}=\Delta y_{t}^{*}+\Delta e_{t}^{I P} \quad \Delta y_{t}^{Y 4}+\Delta u_{t}^{Y 4}=\Delta y_{t}^{*}+\Delta e_{t}^{Y_{4}} .
$$

Idea1ly, we would like to be able to answer the following questions. First, how poorly do the two series measure true production, i.e. how large is the variance of the measurement error relative to the variance of the true series? Second, which of the output measures is a better proxy for output, i.e. for which series is the variance of the measurement error smaller?

Each of the these questions could be answered if we could estimate the population moments $\mathrm{V}\left(\Delta \mathrm{u}^{\mathrm{IP}}\right), \mathrm{V}\left(\Delta \mathrm{e}^{\mathrm{IP}}\right), \mathrm{V}\left(\Delta \mathrm{u}^{\mathrm{Y}}\right), \mathrm{V}\left(\Delta \mathrm{e}^{\mathrm{Y}}\right)$, and $\mathrm{V}\left(\Delta \mathrm{y}^{*}\right)$. Under the assumptions given so far, these moments are related to the moments of the measured series as follows:

$$
\begin{aligned}
& \operatorname{var}\left(\Delta \mathrm{y}_{t}^{\mathrm{IP}}\right)=\operatorname{var}\left(\Delta \mathrm{y}_{t}^{*}\right)+\operatorname{var}\left(\Delta_{t}^{\mathrm{IP}}\right)-\operatorname{var}\left(\Delta \mathrm{u}_{t}^{\mathrm{IP}}\right) \\
& \operatorname{var}\left(\Delta \mathrm{y}_{t}^{\mathrm{Y}}\right)=\operatorname{var}\left(\Delta \mathrm{y}_{t}^{*}\right)+\operatorname{var}\left(\Delta \mathrm{e}_{t}^{\mathrm{Y}}\right)-\operatorname{var}\left(\Delta \mathrm{u}_{t}^{\mathrm{Y}}\right) \\
& \operatorname{cov}\left(\Delta \mathrm{y}_{t}^{\mathrm{IP}}, \Delta \mathrm{y}_{t}^{\mathrm{Y}}\right)=\operatorname{var}\left(\Delta \mathrm{y}_{t}^{*}\right)-\operatorname{var}\left(\Delta \mathrm{u}_{t}^{\mathrm{Y}}\right)-\operatorname{var}\left(\Delta \mathrm{u}_{t}^{\mathrm{IP}}\right) .
\end{aligned}
$$


Unfortunately, obtaining three sample moments does not enable us to estimate five population moments (although we can estimate certain combinations of the moments).

As an example of the difficulties with inference, note that a large variance of e type measurement error tends to increase the variance of measured output, but a large variance of $u$ type measurement error tends to decrease the variance of measured output. Thus, observing (as we have) that the $\log$ growth rate of IP has a smaller variance than Y4 could mean that IP is a better series (smaller classical type measurement error) or that IP is a worse series (larger artificial smoothing or larger rational forecast error). ${ }^{33}$ Distinguishing between these possibilities and estimating the relevant parameters requires either additional identifying assumptions or additional information.

In part A below, we calculate the importance of measurement error under the assumption that all measurement error is of the e type. In the following sub-section, we make the calculations under the other extreme assumption that all measurement error is of the $u$ type. In each case, we use the sample moments to estimate the fractions $\left(\kappa^{I P}, \kappa^{\mathrm{Y}}\right)$ of the total variance of each series that is due to measurement error in that series, and the ratio $\left(\lambda^{\text {IP }}\right.$ ) of the variance of the measurement error in IP to the sum of the variances of the measurement error in IP and Y4. Under the assumptions in this paper, the optimal indicator of the true series based

${ }^{33}$ As long as the serial correlation in the growth rate of the measurement errors is less than that in the growth rate of the true series, higher measurement error variance decreases the autocorrelation of the growth rate of the measured series in a model with only e type measurement error, while higher measurement error variance increases the autocorrelation of the growth rate of the measured series with only $u$ type measurement error. Thus, the fact that the growth rate of $Y 4$ has a lower autocorrelation than IP could again be evidence of a large e type measurement error in $\mathrm{Y}_{4}$ or a large $u$ type measurement error in IP. 
solely on the contemporaneous observations is a linear combination of the two series, and the weight on IP is equal to $\lambda^{\text {IP }} \cdot 34$ Finally, in part $C$ we attempt to use information about the differences in construction of IP across industries to shed light on which type of measurement error is likely to be most important.

\section{A. Classical Measurement Error (e).}

Assume for the moment that $\mathrm{v}\left(\Delta \mathrm{u}^{\mathrm{IP}}\right)=\mathrm{v}\left(\Delta_{\mathrm{u}}^{\mathrm{Y}}\right)=0$ so that all measurement error is the classical type. Under this assumption, $\operatorname{Cov}\left(\Delta y^{I P}\right.$, $\left.\Delta y^{Y 4}\right)=V\left(\Delta y^{*}\right) .35$ In the absence of measurement error, a regression of one series on the other would yield a coefficient of unity. With e type measurement error, the coefficient will be biased downward, and the bias (the difference between unity and the coefficient) will be a consistent estimate of $\kappa$ for the right hand side variable. ${ }^{36}$ Thus, regressing IP on Y4

${ }^{34}$ See de Leeuw and McKelvey (1983) for the case of e type measurement error. An analogous argument carries through for u type measurement error. These each assume that the optimal weights sum to one, which might not be the case if some weight is put on the unconditional mean. Also, if the first differences of the measurement error are serially correlated, a superior indicator could be constructed using both contemporaneous and past values of the two series.

${ }^{35}$ Prescott (1986) makes this observation and estimates the variance of true hours of employment based on household and firm measures of hours. Lichtenberg and Griliches (1986) also assume that only classical measurement error is present and estimate the same variance ratios as we do in this subsection for two measures of output prices. They examine long run inflation rates and base their measurement error estimates on sample moments computed across industries for a single time period, rather than across time for a single industry as is done here.

${ }^{36} \mathrm{Call} \hat{\beta}_{\mathrm{Y} 4 \text {, IP }}$ the estimated coefficient when $\Delta \mathrm{y}^{\mathrm{Y} 4}$ is regressed on $\Delta y^{I P}$. Then $\operatorname{plim}\left(1-\beta_{\mathrm{Y} 4, \mathrm{IP}}\right)=1-\operatorname{cov}\left(\Delta \mathrm{y}^{\mathrm{IP}}, \Delta \mathrm{y}^{\mathrm{Y}}\right) / \operatorname{var}\left(\Delta \mathrm{y}^{\mathrm{IP}}\right)$

$=1-\operatorname{var}\left(\Delta \mathrm{y}^{*}\right) /\left[\left(\operatorname{var}\left(\Delta \mathrm{y}^{*}\right)+\operatorname{var}\left(\Delta \mathrm{e}^{\mathrm{IP}}\right)\right]-\operatorname{var}\left(\Delta \mathrm{e}^{\mathrm{IP}}\right) /\left[\left(\operatorname{var}\left(\Delta \mathrm{y}^{*}\right)+\operatorname{var}\left(\Delta \mathrm{e}^{\mathrm{IP}}\right)\right]\right.\right.$ $-\operatorname{var}\left(\Delta \mathrm{e}^{\mathrm{IP}}\right) / \operatorname{var}\left(\Delta \mathrm{y}^{\mathrm{IP}}\right)=\kappa^{\mathrm{IP}}$. 
gives us information about the measurement error in $\mathrm{Y} 4$, and regressing $\mathrm{Y} 4$ on IP gives us information about the measurement error in IP. ${ }^{37}$

The results are presented in Table 4. Looking at the seasonally adjusted data, these estimates indicate that in all but one industry at least 608 of the variation in the growth rate of $\mathrm{Y} 4$ is due to measurement error, and in 16 out of 20 industries it is over 808 . Looking at IP, we find that in 15 out of 20 industries measurement error accounts for over 358 of the variation in the monthly growth rate. The estimated standard errors of the ratios indicate that in most cases they are estimated precisely. When we turn to the seasonally unadjusted data, we find a different set of results. Relative to the seasonally adjusted data, the measurement error shares are estimated to be smaller for Y4 and IP, and of ten negative for IP. The ratios would be expected to be smaller if seasonality in the measurement error were small relative to the seasonality in the true series. However, the negative estimates suggest a misspecification, to which we return in subsection $C^{38}$

The seasonally adjusted results in Table 4 indicate that the optimal weight $\lambda^{\mathrm{IP}}\left(-\mathrm{V}\left(\Delta \mathrm{e}^{\mathrm{Y} 4}\right) /\left[\mathrm{V}\left(\Delta \mathrm{e}^{\mathrm{Y}}\right)+\mathrm{V}\left(\Delta \mathrm{e}^{\mathrm{IP}}\right)\right]\right)$ is in all but one case significantly greater than $.5 .^{39,40}$ This indicates that under the

${ }^{37}$ Using this simple regression technique has the advantage of enabling us to calculate in a straightforward way the standard errors of these variance ratios. We employ the Hansen and Hodrick (1980) procedure, as modified by Newey and West (1987), to calculate standard errors that are consistent given the serial correlation in the residuals.

${ }^{38}$ We also calculated the tables using seasonal dummy adjusted data, and the results were similar to the SA results in Table 4.

${ }^{39}$ We again use a simple regression technique to calculate an estimate of $\lambda^{I P}$ and its standard error. The coefficient in the regression of $\Delta y^{Y 4}$ on $\Delta y^{Y 4}-\Delta y^{I P}$ is a consistent estimate of $\lambda^{I P}$. 
assumption that all measurement error is of the classical (e) type, IP is the better measure of output: the variance in its measurement error is less, and an optimal indicator would place more weight on it. However, there is evidence of substantial measurement error in both series.

\section{B. u Type Measurement Error}

In this section, we make the opposite polar assumption: $V\left(\Delta e^{I P}\right)=$ $\mathrm{V}\left(\Delta \mathrm{e}^{\mathrm{Y}}\right)=0$, so that all measurement error is orthogonal to the measured series. Here we define $\kappa^{I P}$ as the variance of the measurement error as a fraction of the variance in the true series ${ }^{41}$, and $\lambda^{I P}$ is defined as $\mathrm{V}\left(\Delta \mathrm{u}^{\mathrm{Y}}\right) /\left[\mathrm{V}\left(\Delta \mathrm{u}^{\mathrm{IP}}\right)+\mathrm{V}\left(\Delta \mathrm{u}^{\mathrm{Y}}\right)\right]$. These numbers are presented in Table $5 .{ }^{42}$

Looking at the SA data, the $\kappa s$ indicate that measurement error continues to represent a substantial part of the variation in each series. The numbers for IP are in all but three cases greater than 608 . The ratios for $Y_{4}$ are generally in the neighborhood of 10-20\%. Note that $\lambda^{\text {IP }}$ in this table is exactly one minus the value of $\lambda^{\text {IP }}$ in Table 4. In other words, while the numbers in Table 4 indicate that $\mathrm{Y} 4$ contains more measurement error than IP, the numbers in Table 5 calculated under the alternative

${ }^{40}$ The seasonally unadjusted results indicate that the optimal weight on IP is greater than one, again suggesting the possibility of misspecification.

${ }^{41}$ We scale by the variance of $\Delta y *$ rather than $\Delta y$, so that the ratio will be interpretable as a fraction between zero and one (recall that in this model, $\left.\mathrm{V}\left(\Delta \mathrm{y}^{*}\right)=\mathrm{V}(\Delta \mathrm{y})+\mathrm{V}(\Delta \mathrm{u})\right)$.

${ }^{42}$ We estimate $\kappa^{\text {IP }}$ by estimating:

1- $\left[\mathrm{V}\left(\Delta \mathrm{y}^{\mathrm{IP}}\right) /\left(\mathrm{V}\left(\Delta \mathrm{y}^{\mathrm{IP}}\right)+\mathrm{V}\left(\Delta \mathrm{y}^{\mathrm{Y}}\right)-\operatorname{Cov}\left(\Delta \mathrm{y}^{\mathrm{IP}}, \Delta \mathrm{y}^{\mathrm{Y}}\right)\right)\right]$ which, under these assumptions, is equal to $\mathrm{V}\left(\Delta \mathrm{u}^{\mathrm{IP}}\right) / \mathrm{V}\left(\Delta \mathrm{y}^{\star}\right)$. Reversing IP and $\mathrm{Y} 4 \mathrm{~g}$ gives us the analogous ratio for $\mathrm{Y} 4$. 
assumption about the type of measurement error suggest the opposite conclusion: that the measurement error in IP is worse than that in $\mathrm{Y} 4$.

The seasonally unadjusted results are also in Table 5.

Unfortunately, the negative estimates for $\kappa^{\mathrm{Y}}$ and $\lambda^{\mathrm{IP}}$ again suggest a misspecification in the NSA data.

C. Including Both Types of Measurement Error and Attempting to Distinguish between them.

What can be said if we are not willing to take as strong a stand as to which type of measurement error is present in the two series? We make two observations. First, by combining sample moments we can estimate the sum of the variances of $\Delta e^{Y 4}$ and $\Delta u^{I P}$ and also the sum of the variances of $\Delta \mathrm{e}^{\mathrm{IP}}$ and $\Delta \mathrm{u}^{\mathrm{Y}}$. The ratio of the $\kappa s$ in table 5 indicates that the former sum is dramatically greater than the latter. ${ }^{43}$ Thus, $e^{\mathrm{Y} 4}$ and $\mathrm{u}^{\mathrm{IP}}$ together appear to constitute the primary sources of measurement error. However, we cannot tie down the importance of $e^{\mathrm{Y} 4}$ relative to that of $\mathrm{u}^{\mathrm{IP}}$.

Second, the fact that there is no issue in producing $\mathrm{Y} 4$ about adjustments for missing productivity shocks suggests that $\mathrm{u}^{\mathrm{Y}}{ }^{4}$ may be an unimportant source of measurement error. In this case, the estimates of the

${ }^{43}$ Under the model with both e and u type errors,

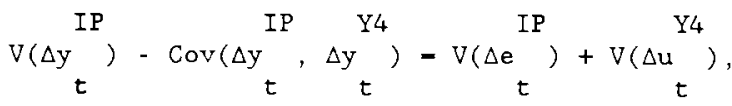

$$
\begin{aligned}
& \mathrm{V}\left(\mathrm{yy}_{t}^{\mathrm{Y}}\right)-\operatorname{Cov}\left(\Delta \mathrm{y}_{t}^{\mathrm{IP}}, \Delta_{t} \mathrm{y}^{\mathrm{Y}}\right)=\mathrm{V}\left(\Delta \mathrm{e}_{t}^{\mathrm{Y}}\right)+\mathrm{V}\left(\Delta_{t}^{\mathrm{IP}}\right) .
\end{aligned}
$$

The ratio of $\kappa^{I P}$ to $\kappa^{\mathrm{Y} 4}$ in Table 5 is equal to $\left[\mathrm{V}\left(\Delta \mathrm{e}^{\mathrm{Y} 4}\right)+\mathrm{V}\left(\Delta \mathrm{u}^{\mathrm{IP}}\right)\right] /\left[\mathrm{V}\left(\Delta \mathrm{e}^{\mathrm{IP}}\right)\right.$ $\left.+\mathrm{V}\left(\Delta \mathrm{u}^{\mathrm{Y}}\right)\right]$. 
size of e type measurement error in IP in Table 4 are accurate estimates, whether or not there is u type measurement error in IP.

While we have exhausted all of the information in the sample moments within each industry, we next consider using information about variations in moments and construction of the IP data across industries. An important part of the measurement error in IP may be due to the fact that a large number of the individual IP series are constructed from input data. Theoretically, the use of input data could add either e type measurement error because it involves added noise, or u type error because the use of inputs to measure output may omit productivity changes. ${ }^{44}$ If the error induced by the use of input data is primarily of the smoothing variety $\left(u^{I P}\right.$ ), then industries based most on input data should exhibit the most smoothing, and thus should have the lower variance (relative to that of Y4). However, if the use of input data simply causes more classical measurement error $\left(e^{I P}\right)$, the high input data industries should have relatively high variance. We estimate the Spearman rank correlation between the use of input data (as reported in Table 1) and the difference of the variances of IP and $\mathrm{Y} 4$ to be -.48 and -.78 for SA and NSA data respectively, each significant at the 58 level. 45

This negative correlation provides evidence that u type measurement error is present in the IP data and is related to the use of inputs. The interpretation is that the use of inputs for IP serves to artificially smooth the data and therefore that the relatively low standard deviation

${ }^{44}$ As indicated previously, the FRB attempts to correct for this by using cyclically adjusted PFCs. Here we allow for the possibility that this adjustment does not fully capture productivity changes.

${ }^{45}$ The spearman correlations between the ratio of variances and the use of input are even stronger: -.75 and -.82 for SA and NSA data respectively. 
of IP should not necessarily be taken to mean that it is a better measure of true output. 46

One final point, suggested by the NSA results, concerns the possibility that the true coefficients relating IP and $\mathrm{Y} 4$ to $\mathrm{y} *$ are not equal to one. Recall that in the model above, the regression of IP on Y4 and the regression of $\mathrm{Y} 4$ on IP each give a coefficient that is biased downward from the true coefficient of one. However, in the NSA results, the regression of $\mathrm{Y}_{4}$ on IP in many cases gave a coefficient greater than one, causing the negative estimates of $\kappa^{\mathrm{IP}}$ in Table 4 and $\kappa^{\mathrm{Y}} 4$ in Table 5 . When the FRB does productivity adjustments within the year, they assume (approximately) that the elasticity of output with respect to inputs is equal to one. They then modify this judgementally to account for cyclical factors, and make no adjustment for seasonal factors. If the elasticity of output with respect to inputs is in fact greater than one, due to either labor hoarding or productivity shocks correlated with input use, then the FRB procedure would bias upward the coefficient in the regression of $\mathrm{Y} 4$ on IP. In fact, there is a strong positive rank correlation (.65) between the use of inputs and the regression coefficient of Y4 on IP using NSA data. Users of NSA data should thus be aware that in the industries based

${ }^{46}$ If an important source of both $e^{I P}$ and $u^{I P}$ is the use of input data, then those industries that are based more on physical product data (and thus less on input data) should have lower total measurement error. In the general model, $\mathrm{V}\left(\Delta \mathrm{y}^{\mathrm{IP}}-\Delta \mathrm{y}^{\mathrm{Y}}\right)=\mathrm{V}\left(\Delta \mathrm{e}^{\mathrm{IP}}\right)+\mathrm{V}\left(\Delta \mathrm{u}^{\mathrm{IP}}\right)+\mathrm{V}\left(\Delta \mathrm{e}^{\mathrm{Y}}\right)+\mathrm{V}\left(\Delta \mathrm{u}^{\mathrm{Y}}\right)$. Under the assumption that the measurement error in $Y 4$ is unrelated to the use of inputs in IP, the rank correlation between the use of inputs and $V\left(\Delta y^{I P}-\Delta y^{Y 4}\right)$ should be positive. The spearman correlations are equal to .40 and .54 for SA and NSA data respectively. Thus the signs of the coefficients are consistent with the above hypothesis, but only the latter is statistically significant at the 5 o level. 
primarily on inputs, the seasonal movements in IP appear to significantly understate the true seasonal variation in output.

The problem raised in the previous paragraph may be present in the SA data as well, although the fact that the coefficients are almost never greater than one in the SA data suggests that this may be less of a problem in SA data. Even if it is present in the SA data, this will bias downward the estimates of e type measurement error in IP in Table 4, i.e. even if this is an issue, we can still conclude that measurement error is an important part of industrial production under an e type model of measurement error.

\section{VI, Concluding Remarks}

In this paper we have documented the radically different time series properties of two different measures of monthly manufacturing output.

Under specific assumptions about the nature of the measurement error, we estimate that a large fraction of the variation in the observed growth rate of both measures of output is due to measurement error. These results suggest that empirical analyses that rely heavily on the time series properties of the month to month variation in either of these measures may give very misleading results.

There are ample reasons for the presence of noise in both series. For Y4, real monthly inventory changes are extremely difficult to estimate from book value data. For IP, the use of inputs to proxy for output involves strong assumptions about productivity. In both cases, there is likely to be standard sampling error.

We find evidence that the error is concentrated in the sum of $e^{\mathrm{Y} 4}$ and $u^{I P}$, and that the use of inputs adds to $u^{I P}$, thus artificially smoothing the data. Unfortunately, we are unable to estimate the importance of $u^{\text {IP }}$ 
relative to $\mathrm{e}^{\mathrm{Y}}$, so we cannot unambiguously recommend one measure over the other. The finding that most of the measurement error is in $u^{I P}$ or $e^{Y 4}$, however, is likely to be useful in certain contexts in choosing between these two measures of production. 


\section{References}

Belsley, David A., 1969, Industrial production behavior: The order-stock distinction (North-Holland, Amsterdam).

Blinder, Alan, 1986, "Can the production smoothing model of inventory behavior be saved?" Quarterly Journal of Economics 101 (August), 431-453.

Campbell, John Y. and N. Gregory Mankiw, 1988, "International evidence on the persistence of economic fluctuations," NBER Working Paper No. 2498.

de Leeuw, Frank and Michael J. McKelvey, 1983, "A 'true' time series and its indicators," Journal of the American Statistical Association 7 (March), $37-46$.

Eichenbaum, Martin S., 1984, "Rational expectations and the smoothing properties of inventories of finished goods," Journal of Monetary Economics 14, 71-96.

Federal Reserve Board, 1986, Industrial production (Federal Reserve Board, Washington, D.C.).

Foss, Murray F., Gary Fromm and Irving Rottenberg, 1980, Measurement of business inventories (Government Printing office, Washington, D.C.).

Hansen, Lars P. and Robert J. Hodrick, 1980, "Forward rates as optimal predictors of future spot rates: An econometric analysis," Journal of Political Economy 88, 5 (October), 829-853.

Harrison, Alan and Mark Stewart, 1986, "Conditional strike-settlement probabilities and the cost of a strike," manuscript, McMaster University (May).

Hinrichs, John C, and Anthony D. Eckman, 1981, "Constant dollar manufacturing inventories," Survey of Current Business 61 (November), 16-23.

Holtz-Eakin, Douglas and Alan Blinder, 1983, "Constant dollar manufacturers' inventories: A note," manuscript, Columbia University.

Kahn, James A., 1987, "Inventories and the volatility of production," American Economic Review 77, 4 (September), 667-679.

Lichtenberg, Frank R, and Zvi Griliches, 1986, "Errors of measurement in output deflators," NBER Working Paper No. 2000 (August).

Maccini, Louis J, and Robert Rossana, 1984, "Joint production, quasi-fixed factors of production, and investment in finished goods inventories," Journal of Money, Credit and Banking 16, 2 (May), 218-36.

Mankiw, N. Gregory, David E. Runkle, and Matthew D. Shapiro, 1984, "Are preliminary announcements of the money stock rational forecasts?" Journal of Monetary Economics 14 (July), 15-27. 
Mankiw, N. Gregory, and Matthew D. Shapiro, 1986, "News or noise: An analysis of GNP revisions," Survey of Current Business (May), 20-25.

Miron, Jeffrey A. and Stephen P. Zeldes, 1988, "Seasonality, cost shocks, and the production smoothing model of irventories," Econometrica, 56, 877 . 908 .

Newey, Whitney $K$. and Kenneth D. West, 1987, "A simple, positive semi definite, heteroscedasticity and autocorrelation consistent covariance matrix," Econometrica 55, 703-708.

Prescott, Edward C., 1986, "Theory ahead of business cycle measurement," Carnegie-Rochester Conference Series 25 (Autumn), 11-44.

Reagan, Patricia and Dennis P. Sheehan, 1985, "The stylized facts about the behavior of manufacturers' Inventories and backorders over the business cycle: 1959-80," Journal of Monetary Economics 15, 217-46.

Sims, Christopher A., 1974, "Output and labor input in manufacturing," Brooking Papers on Economic Activity 3, 695-735.

Stockman, Alan C., 1988, "Sectoral and national aggregate disturbances to industrial output in seven European countries, "Journal of Monetary Economics 21, $387-409$.

U.S. Department of Commerce, Bureau of the Census, 1983, "Census of manufactures, 1977, indexes of production," Washington: GPO.

West, Kenneth D., 1983, "A note on the econometric use of constant dollar inventory series," Economic Letters 13, 337-41.

West, Kenneth D., 1986, "A variance bounds test of the linear quadratic inventory model," Journal of Political Economy 94, 2 (April), 374-401. 


\begin{tabular}{|l|c|c|c|c|c|c|}
\hline \multicolumn{6}{|c|}{ Table 1: Composition of IP, by Source } \\
\hline & SIC & Non-Durable/ & \multicolumn{4}{|c|}{ Fraction of Index Based on } \\
\cline { 4 - 7 } & Code & Durable & Physical & Kilowatt & Prod. Work. & Other \\
& & & Output & Hours & Hours & Data \\
\hline Food & 20 & $\mathrm{~N}$ & .409 & .390 & .200 & .000 \\
Tobacco & 21 & $\mathrm{~N}$ & .903 & .097 & .000 & .000 \\
Textiles & 22 & $\mathrm{~N}$ & .671 & .307 & .022 & .000 \\
Apparel & 23 & $\mathrm{~N}$ & .000 & .165 & .835 & .000 \\
Lumber & 24 & $\mathrm{D}$ & .539 & .035 & .313 & .113 \\
Furniture & 25 & $\mathrm{D}$ & .000 & .953 & .047 & .000 \\
Paper & 26 & $\mathrm{~N}$ & .990 & .000 & .010 & .000 \\
Printing & 27 & $\mathrm{~N}$ & .297 & .703 & .000 & .000 \\
Chemicals & 28 & $\mathrm{~N}$ & .334 & .376 & .227 & .062 \\
Petroleum & 29 & $\mathrm{~N}$ & .924 & .076 & .000 & .000 \\
Rubber & 30 & $\mathrm{~N}$ & .234 & .695 & .000 & .071 \\
Leather & 31 & $\mathrm{~N}$ & .547 & .151 & .302 & .000 \\
Stone,Clay,Glass & 32 & $\mathrm{D}$ & .255 & .628 & .117 & .000 \\
Primary Metal & 33 & $\mathrm{D}$ & .908 & .021 & .071 & .000 \\
Fab Metal & 34 & $\mathrm{D}$ & .000 & .510 & .490 & .000 \\
Machinery & 35 & $\mathrm{D}$ & .005 & .673 & .240 & .082 \\
Elec Machinery & 36 & $\mathrm{D}$ & .134 & .271 & .554 & .041 \\
Trans Equip & 37 & $\mathrm{D}$ & .418 & .005 & .577 & .000 \\
Instruments & 38 & $\mathrm{D}$ & .000 & .173 & .711 & .117 \\
Other & 39 & $\mathrm{D}$ & .000 & 1.000 & .000 & .000 \\
Non-Durables & - & $\mathrm{N}$ & .446 & .363 & .171 & .020 \\
Durables & - & $\mathrm{D}$ & .242 & .348 & .375 & .034 \\
Total & - & $\mathrm{T}$ & .328 & .355 & .289 & .028 \\
\hline
\end{tabular}

Notes:

1. The entries in the last four columns are the fraction of the industrial production index of each industry that is based on physical output data, kilowatt hours data, production worker hours data, and other data, respectively.

2. The Other category includes Federal Reserve estimates and combined kilowatt hour and production worker hour data.

3. Source: Federal Reserve Board, Industrial Production, 1986. 


\begin{tabular}{|c|c|c|c|c|c|c|c|c|c|c|}
\hline & \multicolumn{3}{|c|}{ Mean } & \multicolumn{3}{|c|}{ Standard Dev. } & \multicolumn{3}{|c|}{ Autocorrelation } & \multirow{2}{*}{$\begin{array}{c}\text { Cross } \\
\text { Correl. }\end{array}$} \\
\hline & IP & $\mathrm{Y} 4$ & t-stat & IP & Y4 & t-stat & IP & $\mathrm{Y} 4$ & t-stat & \\
\hline Food & .0025 & .0014 & 1.77 & .009 & .021 & 12.14 & -.27 & -.34 & 0.82 & .18 \\
\hline Tobacco & .0004 & .0002 & 0.12 & .046 & .098 & 7.60 & -.52 & -.45 & -0.64 & .19 \\
\hline Textiles & .0014 & .0016 & -0.16 & .021 & .035 & 3.54 & .31 & -.39 & 5.08 & .25 \\
\hline Apparel & .0010 & .0010 & 0.03 & .024 & .057 & 8.28 & -.23 & -.35 & 1.10 & .09 \\
\hline Lumber & .0015 & .0023 & -0.55 & .026 & .051 & 8.28 & .04 & -.32 & 2.55 & .32 \\
\hline Furniture & .0030 & .0031 & -0.10 & .020 & .061 & 15.24 & .05 & -.51 & 4.96 & .16 \\
\hline Paper & .0028 & .0023 & 0.67 & .019 & .024 & 2.62 & -.02 & -.34 & 1.72 & .38 \\
\hline Printing & .0030 & .0021 & 1.04 & .012 & .033 & 13.14 & -.13 & -.51 & 3.58 & -.02 \\
\hline Chemicals & .0041 & .0030 & 1.54 & .015 & .026 & 8.42 & .10 &. .23 & 2.32 & .17 \\
\hline Petroleum & .0009 & .0017 & -0.60 & .021 & .031 & 3.25 & -.12 & -.37 & 2.45 & .08 \\
\hline Rubber & .0054 & .0023 & 2.29 & .031 & .043 & 2.80 & .09 & -.27 & 3.61 & .37 \\
\hline Leather & -.0028 & -.0032 & 0.21 & .029 & .075 & 13.19 & -.21 & -.44 & 2.28 & .09 \\
\hline Stone,Clay, Glass & .0022 & .0009 & 1.71 & .020 & .034 & 6.99 & -.01 & -.34 & 3.31 & .33 \\
\hline Primary Metal & -.0007 & -.0007 & 0.04 & .041 & .042 & 0.10 & .19 & .10 & 0.86 & .64 \\
\hline Fab Metal & .0013 & .0011 & 0.15 & .014 & .051 & 22.63 & .41 & -.44 & 7.79 & .25 \\
\hline Machinery & .0035 & .0028 & 0.86 & .015 & .039 & 24.99 & .30 & -.35 & 5.39 & .34 \\
\hline Elec Machinery & .0049 & .0045 & 0.40 & .016 & .040 & 16.03 & .16 & -.39 & 5.67 & .29 \\
\hline Trans Equip & .0016 & .0016 & 0.05 & .031 & .058 & 11.95 & .29 & -.07 & 3.56 & .61 \\
\hline Instruments & .0048 & .0041 & 0.48 & .011 & .066 & 50.41 & .09 & -.47 & 5.58 & .25 \\
\hline Other & .0014 & .0013 & 0.03 & .020 & .057 & 13.46 & -.23 & -.38 & 1.52 & .10 \\
\hline Non-Durables & .0028 & .0018 & 2.47 & .009 & .014 & 6.30 & .30 & -.25 & 3.28 & .45 \\
\hline Durables & .0024 & .0021 & 0.64 & .014 & .025 & 14.51 & .47 & -.09 & 5.36 & .59 \\
\hline Total & .0026 & .0019 & 1.88 & .011 & .017 & 8.49 & .44 & -.10 & 4.91 & .61 \\
\hline
\end{tabular}

\section{Notes:}

1. The sample period is $1967: 5-1984: 12$.

2. The statistics in the table are computed for monthly logarithmic growth rates.

3. The Y4 results are based on the finished goods plus work-in-progress definition of output.

4. The t-statistics are for tests of the hypotheses that the relevant moments are the same. 


\begin{tabular}{|c|c|c|c|c|c|c|c|c|c|c|c|}
\hline \multicolumn{12}{|c|}{ Table 2b: Summary Statistics, Seasonally Unadjusted Data } \\
\hline & \multicolumn{3}{|c|}{ Mean } & \multicolumn{3}{|c|}{ Standard Dev. } & \multicolumn{3}{|c|}{ Autocorrelation } & \multirow{2}{*}{\begin{tabular}{|c|} 
Seasonals \\
$\chi^{2}$
\end{tabular}} & \multirow{2}{*}{$\begin{array}{l}\text { Cross } \\
\text { Correl. }\end{array}$} \\
\hline & IP & Y4 & t-stat & IP & Y4 & t-stat & IP & Y4 & t-stat & & \\
\hline Food & .0025 & .0013 & 1.55 & .031 & .047 & 8.58 & .17 & -.10 & 4.24 & 98.0 & .73 \\
\hline Tobacco & -.0009 & -.0006 & -0.09 & .144 & .150 & 0.48 & -.44 & -.37 & -1.15 & 96.9 & .61 \\
\hline Textiles & .0008 & .0011 & -0.19 & .082 & .110 & 8.46 & -.32 & -.41 & 1.62 & 133.7 & .87 \\
\hline Apparel & .0009 & -.0004 & 0.51 & .074 & .124 & 13.50 & -.32 & -.27 & -0.76 & 133.7 & .63 \\
\hline Lumber & .0009 & .0016 & -0.45 & .054 & .086 & 11.77 & -.01 & -.16 & 2.35 & 75.3 & .72 \\
\hline Furniture & .0030 & .0027 & 0.16 & .059 & .115 & 11.04 & -.39 & -.39 & 0.19 & 403.6 & .71 \\
\hline Paper & .0022 & .0017 & 0.65 & .063 & .059 & 1.57 & -.30 & -.39 & 1.67 & 94.1 & .89 \\
\hline Printing & .0030 & .0020 & 0.82 & .038 & .052 & 4.94 & .44 & -.29 & 11.88 & 656.4 & .37 \\
\hline Chemicals & .0040 & .0025 & 1.30 & .027 & .057 & 13.33 & .06 & -.11 & 2.06 & 806.1 & .52 \\
\hline Petroleum & .0011 & .0015 & -0.27 & .032 & .037 & 2.18 & .13 & -.33 & 4.38 & 72.8 & .37 \\
\hline Rubber & .0051 & .0015 & 2.33 & .063 & .084 & 5.78 & -.10 & -.25 & 2.10 & 113.4 & .79 \\
\hline Leather & -.0031 & -.0035 & 0.19 & .082 & .110 & 4.53 & -.39 & -.42 & 0.62 & 66.8 & .62 \\
\hline Stone,Clay, Glass & .0019 & .0003 & 1.68 & .043 & .065 & 10.65 & .10 & -.13 & 4.01 & 205.4 & .74 \\
\hline Primary Metal & .0014 & -.0017 & 0.26 & .064 & .072 & 2.10 & .15 & .02 & 1.91 & 20.7 & .85 \\
\hline Fab Metal & .0012 & .0004 & 0.47 & .026 & .098 & 45.34 & -.07 & -.37 & 4.49 & 326.1 & .63 \\
\hline Machinery & .0033 & .0027 & 0.37 & .029 & .095 & 34.34 & .00 & -.31 & 5.53 & 761.6 & .65 \\
\hline Elec Machinery & .0049 & .0043 & 0.46 & .032 & .091 & 22.81 & .03 & -.28 & 4.30 & 375.5 & .70 \\
\hline Trans Equip & .0014 & .0008 & 0.34 & .070 & .120 & 20.62 & .03 & -.01 & 0.82 & 350.3 & .84 \\
\hline Instruments & .0049 & .0040 & 0.50 & .020 & .101 & 45.07 & -.09 & -.39 & 4.56 & 304.0 & .45 \\
\hline Other & .0012 & .0009 & 0.17 & .049 & .103 & 14.75 & -.07 & -.19 & 1.86 & 134.9 & .62 \\
\hline Non-Durables & .0026 & .0014 & 2.27 & .035 & .045 & 8.88 & -.08 & -.19 & 1.89 & 244.8 & .91 \\
\hline Durables & .0022 & .0016 & 0.61 & .032 & .078 & 24.62 & .01 & -.14 & 3.08 & 766.4 & .89 \\
\hline Total & .0024 & .0015 & 1.25 & .032 & .060 & 21.52 & -.05 & -.16 & 2.07 & 819.7 & .92 \\
\hline
\end{tabular}

Notes:

1. The sample period is $1967: 5-1984: 12$.

2. The statistics in the table are computed for monthly logarithmic growth rates.

3. The Y4 results are based on the finished goods plus work-in-progress definition of output.

4. The t-statistics are for tests of the hypotheses that the relevant moments are the same. The $\chi^{2}$ statistic is for the test of the hypothesis that the seasonal patterns in the log growth rates of IP and Y4 are the same. The $95 \%$ critical value of the $\chi^{2}(11)$ is 19.67 . 


\begin{tabular}{|l|c|c|}
\hline \multicolumn{3}{|c|}{ Table 3: Variance of Production over Variance of Sales, } \\
Seasonally Adjusted Data
\end{tabular}

\section{Notes:}

1. The sample period is 1959:2 -1981:7.

2. The statistics in the tables are computed for deviations from exponential trend; see text for details.

3. The Y4 results are based on the finished goods plus work-in-progress definition of output. 


\begin{tabular}{|l|r|r|r|r|r|r|r|r|r|r|r|r|}
\hline \multicolumn{10}{|c|}{ Table 4: Estimates of “e-typen Measurement Errors } \\
\hline & \multicolumn{7}{|c|}{ Seasonally Adjusted } & \multicolumn{3}{c|}{ Seasonally Unadjusted } \\
\hline & $\hat{\kappa}_{I P}$ & \multicolumn{1}{c|}{ se } & $\hat{\kappa}_{Y 4}$ & \multicolumn{1}{c|}{ se } & $\hat{\lambda}_{I P}$ & se & $\hat{\kappa}_{I P}$ & se & $\hat{\kappa}_{Y 4}$ & se & $\hat{\lambda}_{I P}$ & se \\
\hline Food & .59 & .16 & .92 & .03 & .89 & .03 & -0.10 & .09 & .52 & .04 & 1.09 & .07 \\
Tobacco & .60 & .15 & .91 & .04 & .87 & .05 & 0.37 & .07 & .42 & .09 & .55 & .11 \\
Textiles & .59 & .11 & .84 & .06 & .79 & .08 & -0.17 & .05 & .35 & .03 & 1.37 & .10 \\
Apparel & .79 & .21 & .96 & .03 & .87 & .04 & -0.06 & .07 & .62 & .06 & 1.03 & .04 \\
Lumber & .38 & .19 & .83 & .07 & .89 & .05 & -0.15 & .07 & .55 & .04 & 1.12 & .05 \\
Furniture & .52 & .22 & .95 & .02 & .94 & .03 & -0.39 & .14 & .63 & .02 & 1.19 & .06 \\
Paper & .52 & .10 & .70 & .11 & .68 & .07 & 0.15 & .03 & .06 & .04 & .26 & .15 \\
Printing & 1.07 & .25 & 1.01 & .03 & .87 & .03 & 0.51 & .07 & .73 & .03 & .72 & .05 \\
Chemicals & .71 & .10 & .90 & .04 & .79 & .03 & -0.11 & .14 & .76 & .02 & 1.03 & .04 \\
Petroleum & .88 & .09 & .95 & .04 & .70 & .06 & 0.58 & .06 & .68 & .05 & .60 & .05 \\
Rubber & .49 & .09 & .74 & .07 & .75 & .09 & -0.06 & .03 & .41 & .04 & 1.08 & .10 \\
Leather & .78 & .21 & .97 & .03 & .89 & .03 & 0.17 & .09 & .54 & .03 & .85 & .08 \\
Stone,Clay,Glass & .43 & .10 & .81 & .04 & .85 & .05 & -0.13 & .07 & .51 & .03 & 1.12 & .06 \\
Primary Metals & .35 & .10 & .36 & .10 & .51 & .13 & 0.05 & .06 & .24 & .05 & .85 & .17 \\
Fab. Metals & .09 & .25 & .93 & .02 & .99 & .02 & -1.33 & .26 & .83 & .02 & 1.13 & .01 \\
Machinery & .12 & .12 & .87 & .02 & .98 & .02 & -1.10 & .10 & .80 & .02 & 1.15 & .02 \\
Elec Machinery & .32 & .17 & .88 & .04 & .94 & .03 & -.97 & .13 & .76 & .02 & 1.19 & .03 \\
Trans Equip &. .13 & .10 & .67 & .07 & 1.06 & .05 & -0.44 & .06 & .51 & .03 & 1.42 & .04 \\
Instruments & -.54 & .42 & .96 & .01 & 1.01 & .01 & -1.27 & .28 & .91 & .01 & 1.06 & .01 \\
Other & .72 & .21 & .96 & .02 & .91 & .03 & -0.32 & .14 & .71 & .02 & 1.11 & .04 \\
Non-Durables & .31 & .07 & .71 & .08 & .84 & .05 & -0.17 & .05 & .29 & .03 & 1.55 & .12 \\
Durables &. .07 & .08 & .68 & .04 & 1.03 & .04 & -1.16 & .08 & .63 & .02 & 1.46 & .04 \\
Total & .02 & .09 & .63 & .05 & .99 & .06 & -0.75 & .07 & .52 & .02 & 1.66 & .05 \\
\hline
\end{tabular}

Notes:

1. The sample period is 1967:5-1984:12.

2. The statistics in the table are computed for monthly logarithmic growth rates.

3. The Y4 results are based on the finished goods plus work-in-progress definition of output.

4. $\lambda^{I P}$ is the weight on IP in an optimal forecast of the true series. We estimate $\lambda^{I P}=$ $\operatorname{Cov}\left(\Delta y^{Y_{4}}, \Delta y^{Y_{4}}-\Delta y^{I P}\right) / \operatorname{Var}\left(\Delta y^{Y_{4}}-\Delta y^{I P}\right)$. Under the assumption that $\operatorname{Var}\left(\Delta u^{Y_{4}}\right)=$ $\operatorname{Var}\left(\Delta u^{I P}\right)=0, \lambda^{I P}=\operatorname{Var}\left(\Delta e^{Y \mathbf{4}}\right) /\left(\operatorname{Var}\left(\Delta e^{Y 4}\right)+\operatorname{Var}\left(\Delta e^{I P}\right)\right)$.

5. $\kappa^{I P}$ is the fraction of the variation in $I P$ due to measurement error. We estimate $\kappa^{I P}=$ $1-\operatorname{Cov}\left(\Delta y^{I P}, \Delta y^{Y 4}\right) / \operatorname{Var}\left(\Delta y^{I P}\right)$. Under the assumption that $\operatorname{Var}\left(\Delta u^{Y 4}\right)=\operatorname{Var}\left(\Delta u^{I P}\right)=0$, $\kappa^{I P}=\operatorname{Var}\left(\Delta e^{I P}\right) /\left(\operatorname{Var}\left(\Delta y^{I P}\right) . \kappa^{Y 4}\right.$ is defined similarly. 


\begin{tabular}{|c|c|c|c|c|c|c|c|c|}
\hline \multicolumn{9}{|c|}{ Table 5: Estimates of "u-type" Measurement Errors } \\
\hline & \multicolumn{4}{|c|}{ Seasonally Adjusted } & \multicolumn{4}{|c|}{ Seasonally Unadjusted } \\
\hline & $\hat{\kappa}_{I P}$ & $\hat{\kappa}_{Y_{4}}$ & $\hat{\lambda}_{I P}$ & se & $\hat{\kappa}_{I P}$ & $\dot{\kappa}_{Y 4}$ & $\hat{\lambda}_{I P}$ & se \\
\hline Food & .83 & .10 & .11 & .03 & .54 & -.05 & -.09 & .07 \\
\hline Tobacco & .81 & .12 & .13 & .04 & .31 & .25 & .45 & .11 \\
\hline Textiles & .69 & .18 & .21 & .06 & .38 & -.10 & -.37 & .10 \\
\hline Apparel & .84 & .12 & .13 & .03 & .63 & -.02 & -.03 & .04 \\
\hline Lumber & .76 & .09 & .11 & .07 & .59 & -.06 & -.11 & .05 \\
\hline Furniture & .90 & .05 & .06 & .02 & .71 & -.11 & -.19 & .06 \\
\hline Paper & .53 & .25 & .32 & .11 & .05 & .14 & .74 & .15 \\
\hline Printing & .88 & .13 & .13 & .03 & .57 & .22 & .28 & .05 \\
\hline Chemicals & .73 & .19 & .21 & .04 & .78 & -.02 & -.03 & .04 \\
\hline Petroleum & .68 & .29 & .30 & .04 & .47 & .31 & .40 & .05 \\
\hline Rubber & .59 & .20 & .25 & .07 & .42 & -.03 & -.08 & .10 \\
\hline Leather & .86 & .11 & .11 & .03 & .49 & .09 & .15 & .08 \\
\hline Stone,Clay,Glass & .70 & .13 & .15 & .04 & .54 & -.06 & -.12 & .06 \\
\hline Primary Metals & .27 & .26 & .49 & .10 & .23 & .04 & .15 & .17 \\
\hline Fab. Metals & .92 & .01 & .01 & .02 & .92 & -.11 & -.13 & .01 \\
\hline Machinery & .86 & .02 & .02 & .02 & .89 & -.12 & -.15 & .02 \\
\hline Elec Machinery & .84 & .05 & .06 & .04 & .86 & -.14 & -.19 & .03 \\
\hline Trans Equip & .70 & -.04 & -.06 & .07 & .60 & -.18 & -.42 & .04 \\
\hline Instruments & .97 & -.01 & -.01 & .01 & .96 & -.05 & -.06 & .01 \\
\hline Other & .88 & .08 & .09 & .02 & .76 & -.08 & -.11 & .04 \\
\hline Non-Durables & .63 & .12 & .16 & .08 & .32 & -.12 & -.55 & .12 \\
\hline Durables & .69 & -.02 & -.03 & .04 & .79 & -.25 & -.46 & .04 \\
\hline Total & .62 & .01 & .01 & .05 & .65 & -.26 & -.66 & .05 \\
\hline
\end{tabular}

Notes:

1. The sample period is $1967: 5-1984: 12$.

2. The statistics in the table are computed for monthly logarithmic growth rates.

3. The Y4 results are based on the finished goods plus work-in-progress definition of output.

4. $\lambda^{I P}$ is the weight on IP in an optimal forecast of the true series. We estimate $\lambda^{I P}=1-$ $\operatorname{Cov}\left(\Delta y^{Y 4}, \Delta y^{Y 4}-\Delta y^{I P}\right) / \operatorname{Var}\left(\Delta y^{Y 4}-\Delta y^{I P}\right)$. Under the assumption that $\operatorname{Var}\left(\Delta e^{Y 4}\right)=$ $\operatorname{Var}\left(\Delta e^{I P}\right)=0, \lambda^{I P}=\operatorname{Var}\left(\Delta u^{Y 4}\right) /\left(\operatorname{Var}\left(\Delta u^{Y 4}\right)+\operatorname{Var}\left(\Delta u^{I P}\right)\right)$.

5. $\kappa^{I P}$ is the fraction of the variation in $I P$ due to measurement error. We estimate $\kappa^{I P}=$ $1-\operatorname{Var}\left(\Delta y^{I P}\right) /\left(\operatorname{Var}\left(\Delta y^{I P}\right)+\operatorname{Var}\left(\Delta y^{Y 4}\right)-\operatorname{Cov}\left(\Delta y^{I P}, \Delta y^{Y 4}\right)\right)$. Under the assumption that $\operatorname{Var}\left(\Delta e^{Y 4}\right)=\operatorname{Var}\left(\Delta e^{I P}\right)=0, \kappa^{I P}=\operatorname{Var}\left(\Delta u^{I P}\right) /\left(\operatorname{Var}\left(\Delta y^{*}\right) . \kappa^{Y 4}\right.$ is defined similarly. 
Figures 1-6

FOOD

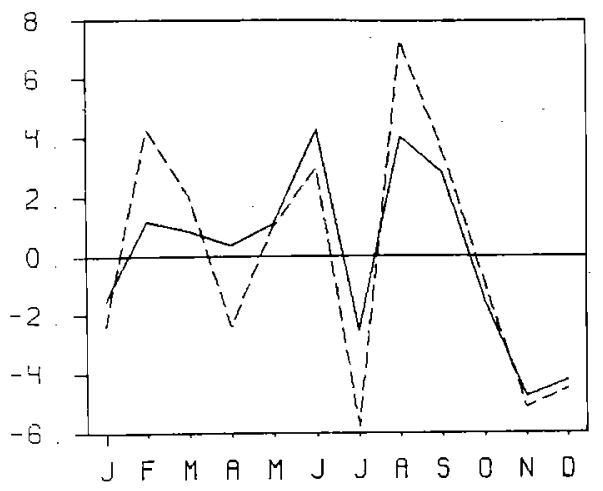

TEXTILES

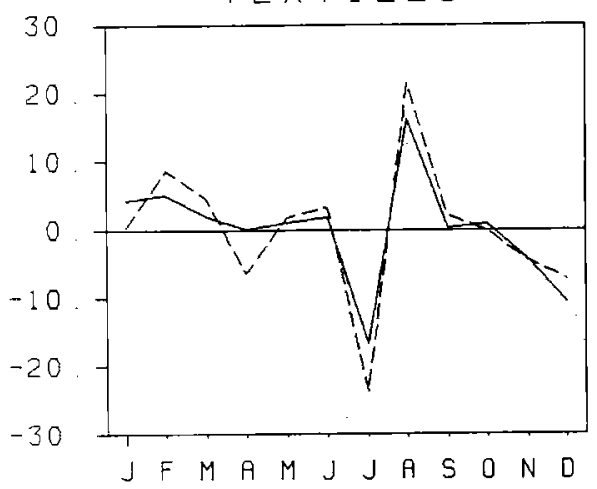

LUMBER

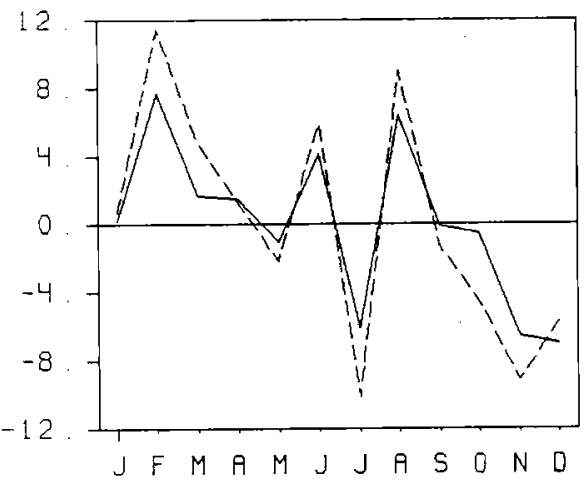

TOBACCO

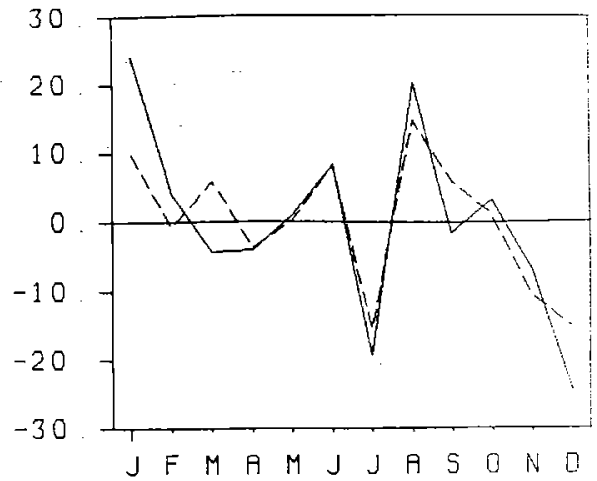

APPAREL

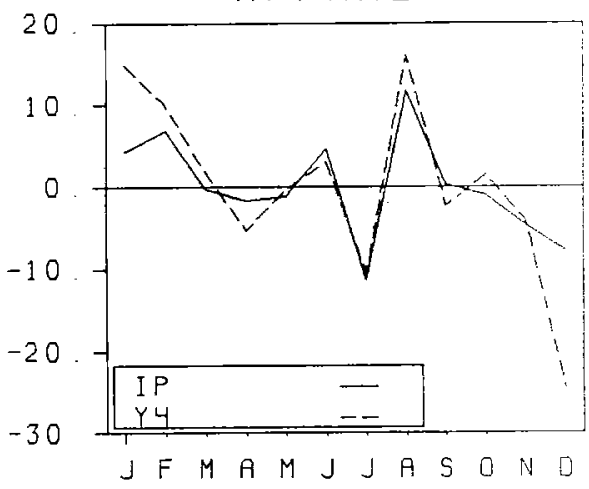

FURN I TURE

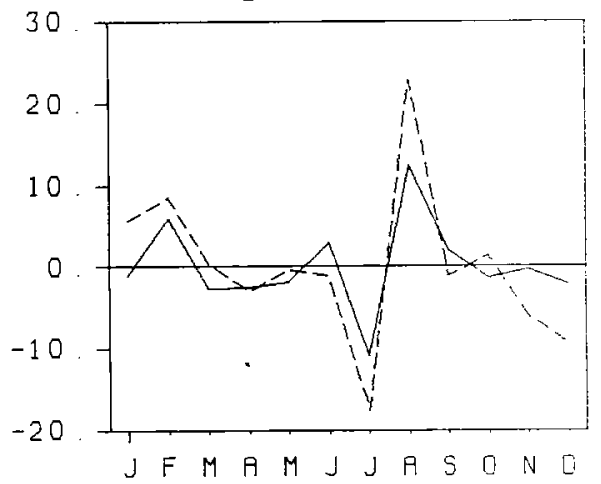


PAPER

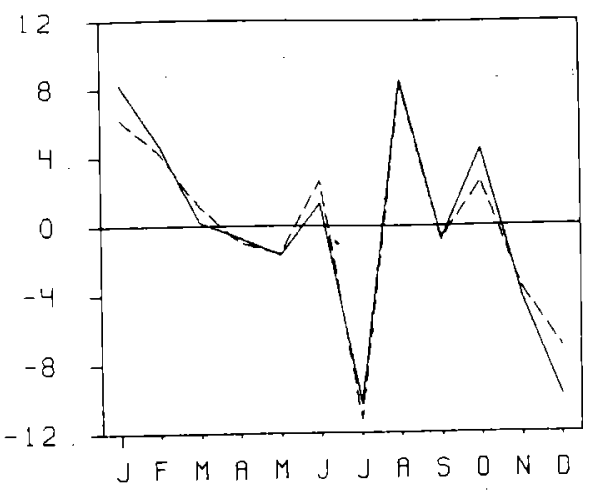

CHEMICALS

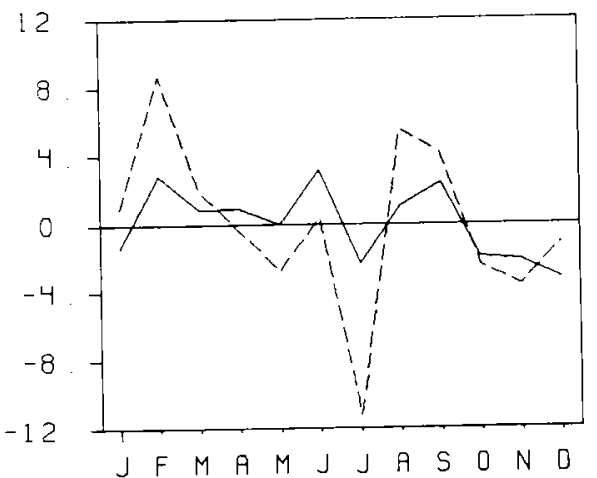

RUBBER

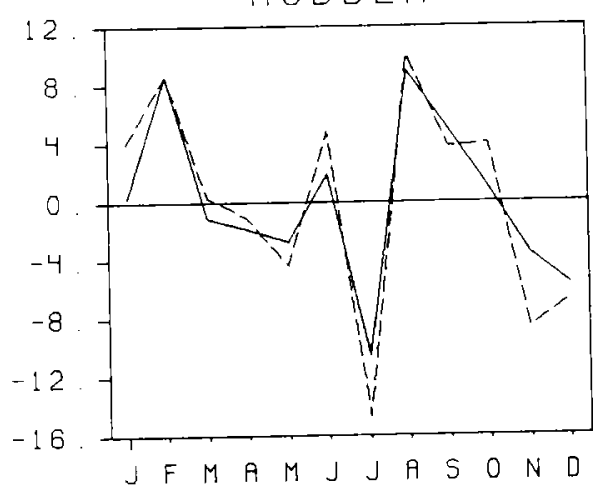

PRINTING

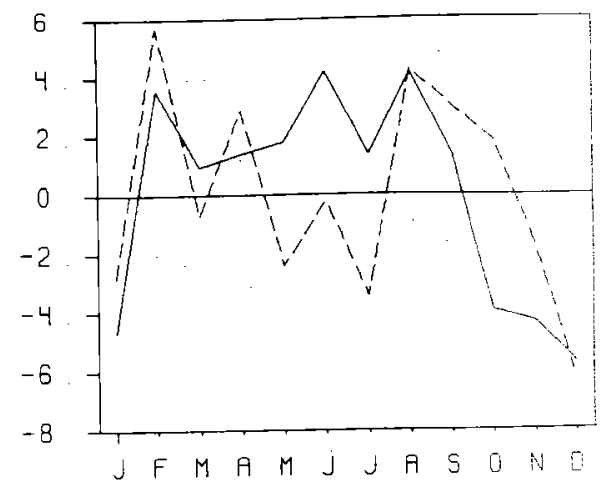

PETROLEUM

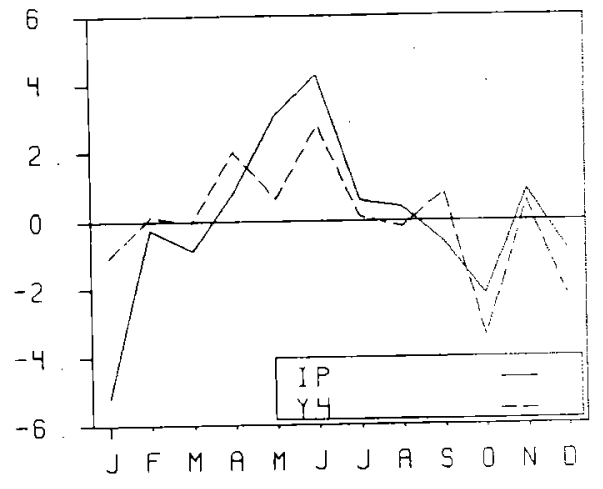

LEATHER

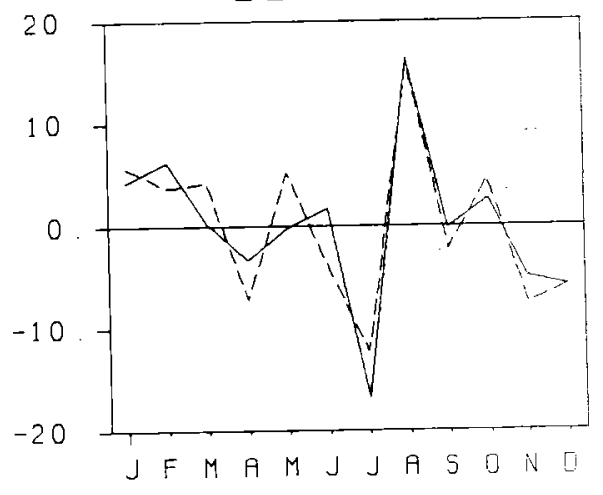


Figures 13-18

STONe, clay, GLASS

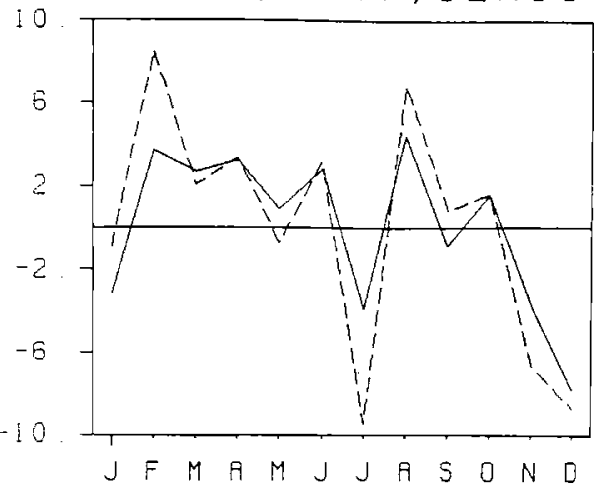

FABRC METALS

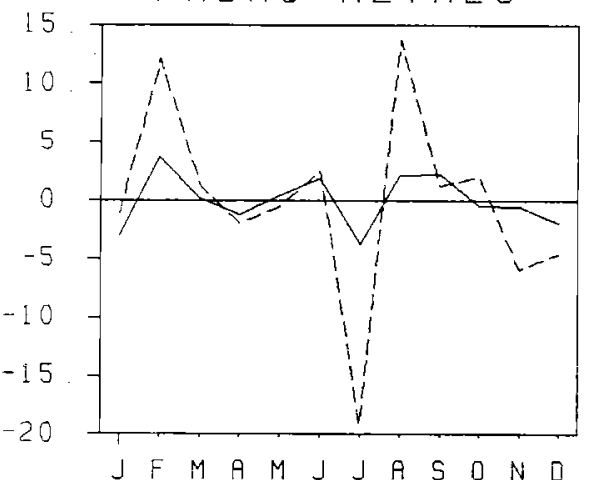

ELECT MACH

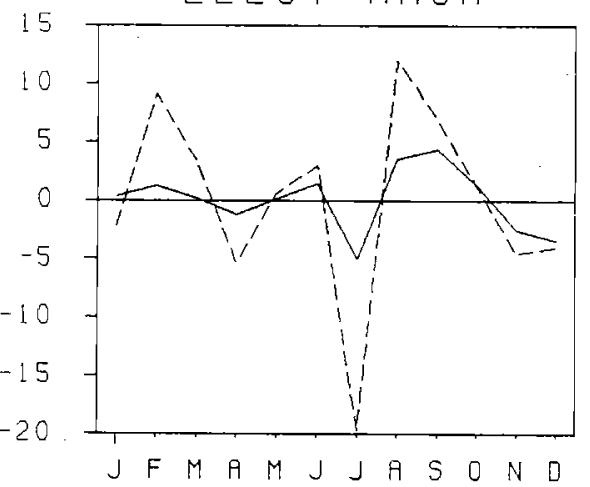

PRIM METRLS

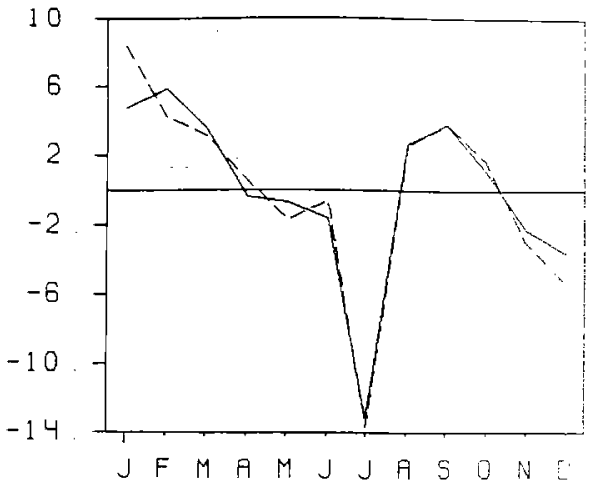

MACHINERY
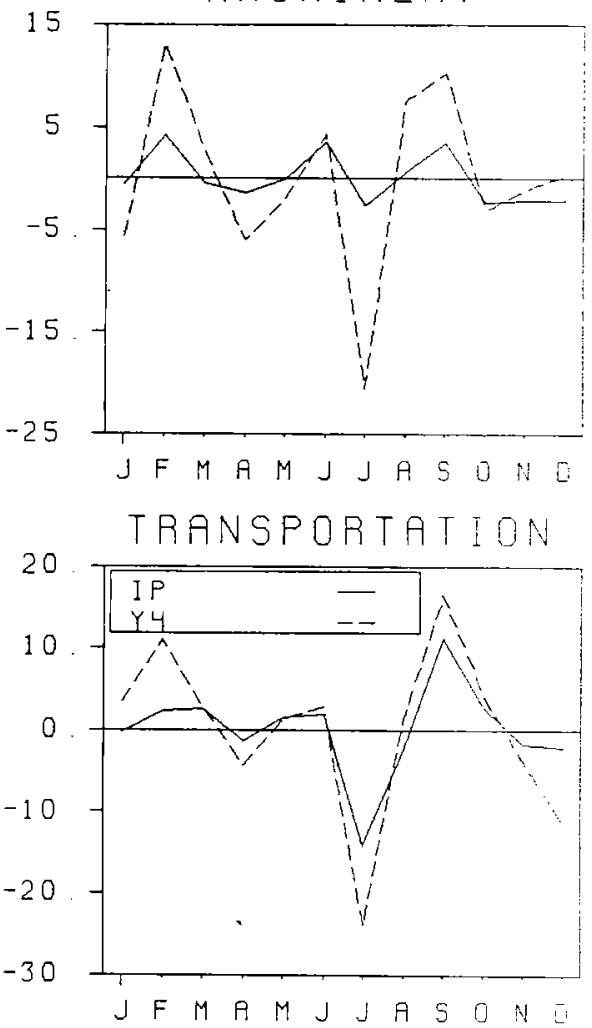
INSTRUMENTS

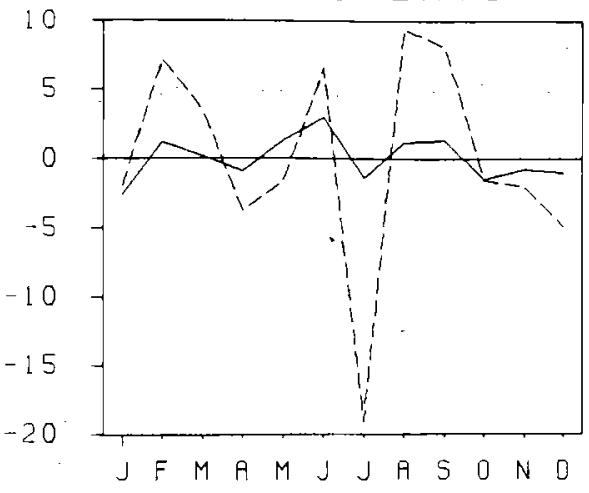

NON-DURABLES

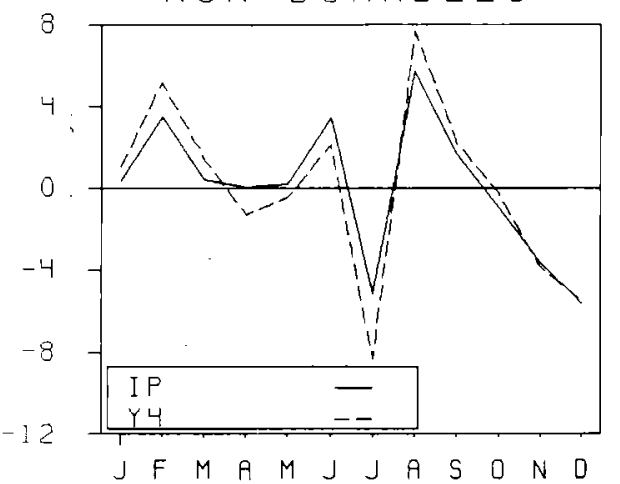

TOTAL MFG

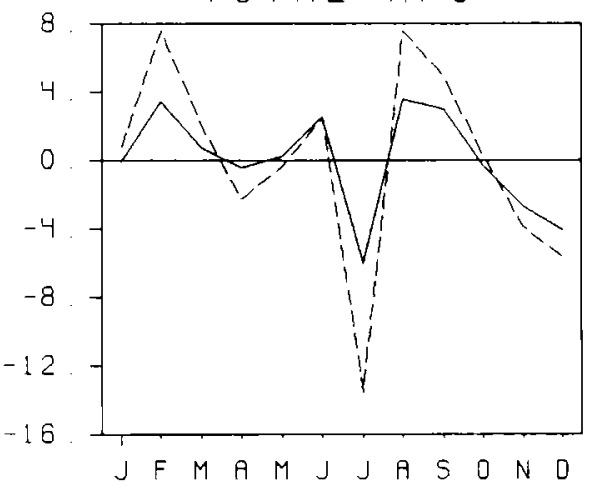

OTHER

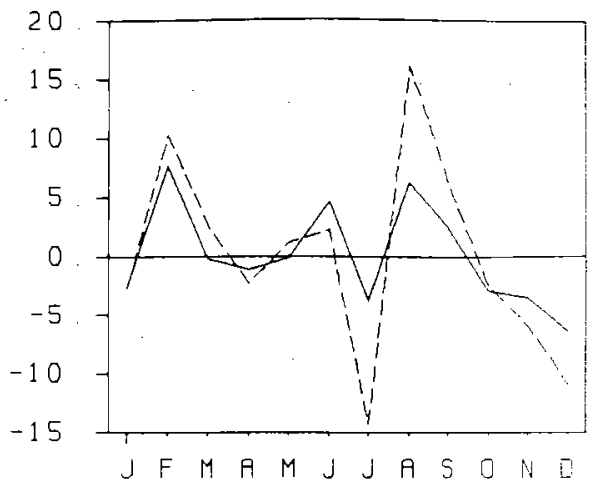

DURABLES

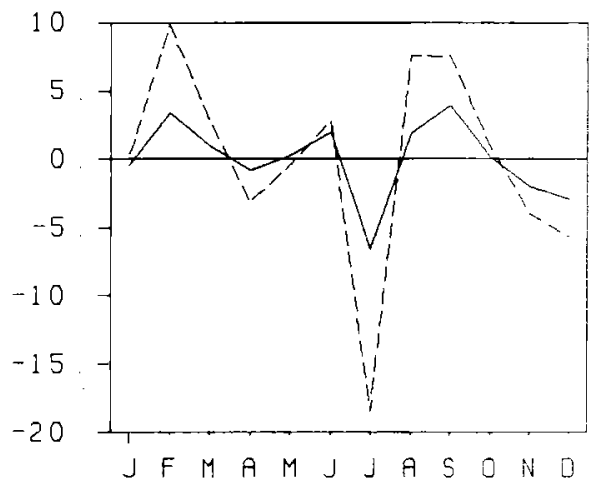


APPENDIX A

RESULTS BASED ON FINISHED GOODS ONLY DEFINITION OF Y4

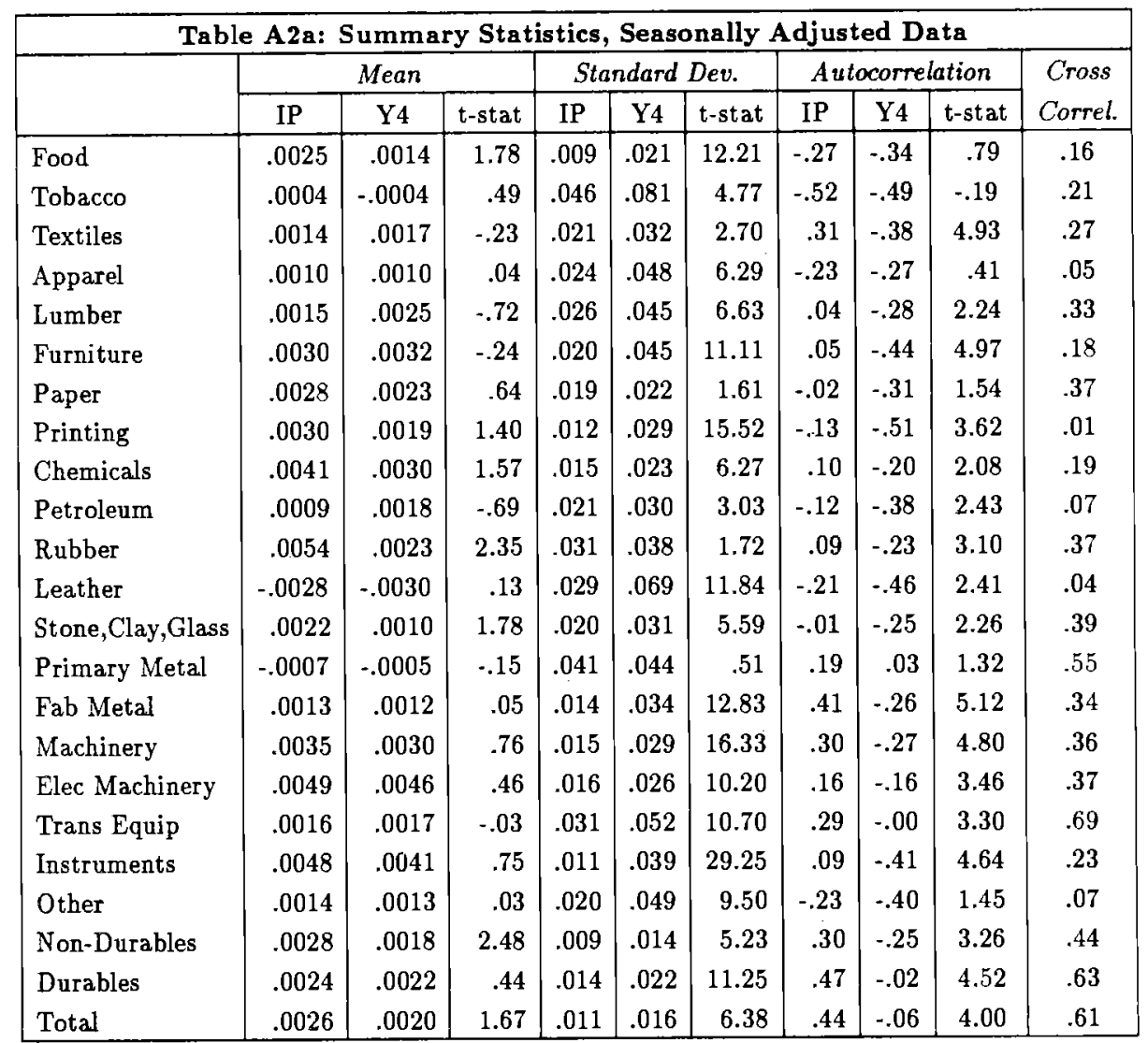

Notes:

1. The sample period is $1967: 5-1984: 12$.

2. The statistics in the table are computed for monthly logarithmic growth rates.

3. The Y4 results are based on the finished goods only definition of output.

4. The t-statistics are for tests of the hypotheses that the relevant moments are the same. 


\begin{tabular}{|c|c|c|c|c|c|c|c|c|c|c|c|}
\hline \multicolumn{12}{|c|}{ Table A2b: Summary Statistics, Seasonally Unadjusted Data } \\
\hline & \multicolumn{3}{|c|}{ Mean } & \multicolumn{3}{|c|}{ Standard Dev. } & \multicolumn{3}{|c|}{ Autocorrelation } & \multirow{2}{*}{$\frac{\text { Seasonals }}{\chi^{2}}$} & \multirow{2}{*}{$\begin{array}{l}\text { Cross } \\
\text { Correl. }\end{array}$} \\
\hline & IP & $\overline{\mathrm{Y} 4}$ & t-stat & IP & $\mathrm{Y} 4$ & t-stat & IP & $\mathrm{Y4}$ & t-stat & & \\
\hline Food & .0025 & .0013 & 1.54 & .031 & .047 & 8.84 & .17 & -.12 & 4.69 & 108.4 & .72 \\
\hline Tobacco & -.0009 & $\because .0005$ & -.14 & .144 & .127 & 1.17 & -.44 & -.51 & 1.23 & 217.1 & .51 \\
\hline Textiles & .0008 & .0013 & -.28 & .082 & .112 & 9.69 & -.32 & -.40 & 1.54 & 128.0 & .86 \\
\hline Apparel & .0009 & -.0003 & .48 & .074 & .122 & 14.20 & -.32 & -.24 & -1.30 & 151.2 & .68 \\
\hline Lumber & .0009 & .0018 & -.57 & .054 & .081 & 10.62 & -.01 & -.17 & 2.22 & 102.3 & .73 \\
\hline Furniture & .0030 & .0029 & .05 & .059 & .112 & 15.60 & -.39 & -.38 & -.04 & 390.9 & .78 \\
\hline Paper & .0022 & .0017 & .52 & .063 & .057 & 2.60 & -.30 & -.37 & 1.27 & 184.1 & .88 \\
\hline Printing & .0030 & .0018 & .99 & .038 & .052 & 5.58 & .44 & -.17 & 9.37 & 1018.7 & .46 \\
\hline Chemicals & .0040 & .0025 & 1.26 & .027 & .056 & 12.82 & .06 & -.12 & 2.18 & 798.5 & .52 \\
\hline Petroleum & .0011 & .0017 & -.40 & .032 & .036 & 1.77 & .13 & -.28 & 3.75 & 37.4 & .42 \\
\hline Rubber & .0051 & .0015 & 2.40 & .063 & .081 & 4.17 & -.10 & -.19 & 1.27 & 131.5 & .81 \\
\hline Leather & -.0031 & -.0033 & .11 & .082 & .108 & 3.92 & -.39 & -.39 & .02 & 70.8 & .65 \\
\hline Stone,Clay,Glass & .0019 & .0003 & 1.80 & .043 & .066 & 12.32 & .10 & -.01 & 1.93 & 316.5 & .81 \\
\hline Primary Metal & -.0014 & -.0013 & -.03 & .064 & .075 & 3.37 & .15 & .01 & 1.80 & 42.4 & .83 \\
\hline Fab Metal & .0012 & .0007 & .36 & .026 & .081 & 46.83 & -.07 & -.33 & 3.96 & 194.2 & .73 \\
\hline Machinery & .0033 & .0030 & .15 & .029 & .101 & 37.47 & .00 & -.36 & 6.70 & 1058.5 & .63 \\
\hline Elec Machinery & .0049 & .0045 & .34 & .032 & .085 & 17.32 & .03 & .30 & 4.92 & 954.5 & .70 \\
\hline Trans Equip & .0014 & .0010 & .21 & .070 & .124 & 16.81 & .03 & -.04 & 1.57 & 463.1 & .89 \\
\hline Instruments & .0049 & .0042 & .48 & .020 & .082 & 48.82 & -.09 & -.35 & 3.72 & 482.8 & .57 \\
\hline Other & .0012 & .0008 & .20 & .049 & .106 & 21.46 & -.07 & -.18 & 1.84 & 206.4 & .68 \\
\hline Non-Durables & .0026 & .0015 & 2.13 & .035 & .046 & 9.65 & -.08 & -.22 & 2.47 & 263.5 & .91 \\
\hline Durables & .0022 & .0018 & .36 & .032 & .081 & 20.67 & .01 & -.18 & 4.05 & 736.6 & .90 \\
\hline Total & .0024 & .0017 & .99 & .032 & .062 & 18.27 & -.05 & -.21 & 2.91 & 537.4 & .91 \\
\hline
\end{tabular}

Notes:

1. The sample period is 1967:5-1984:12.

2. The statistics in the table are computed for monthly logarithmic growth rates.

3. The Y4 results are based on the finished goods only definition of output.

4. The t-statistics are for tests of the hypotheses that the relevant moments are the same. The $\chi^{2}$ statistic is for the test of the hypothesis that the seasonal patterns in the log growth rates of IP and Y4 are the same. The $95 \%$ critical value of the $\chi^{2}(11)$ is 19.67 . 


\begin{tabular}{|c|c|c|c|c|c|c|c|c|c|c|c|c|}
\hline \multicolumn{13}{|c|}{ Table A4: Estimates of "e-type" Measurement Errors } \\
\hline & \multicolumn{6}{|c|}{ Seasonally Adjusted } & \multicolumn{6}{|c|}{ Seasonally Unadjusted } \\
\hline & $\hat{\kappa}_{I P}$ & se & $\hat{\kappa}_{Y 4}$ & $\mathrm{se}$ & $\hat{\lambda}_{I P}$ & se & $\hat{\kappa}_{I P}$ & se & $\hat{k}_{Y 4}$ & se & $\hat{\lambda}_{I P}$ & se \\
\hline Food & .65 & .15 & .93 & .03 & .88 & .03 & -.09 & .08 & .52 & .04 & 1.08 & .07 \\
\hline Tobacco & .63 & .16 & .88 & .05 & .81 & .07 & .55 & .05 & .42 & .12 & .37 & .11 \\
\hline Textiles & .60 & .10 & .82 & .06 & .76 & .10 & -.18 & .05 & .37 & .03 & 1.35 & .09 \\
\hline Apparel & .90 & .20 & .98 & .05 & .81 & .05 & -.11 & .07 & .59 & .06 & 1.07 & .04 \\
\hline Lumber & .45 & .14 & .81 & .07 & .84 & .05 & -.10 & .07 & .52 & .04 & 1.09 & .06 \\
\hline Furniture & .61 & .14 & .92 & .03 & .88 & .03 & -.49 & .11 & .59 & .02 & 1.30 & .05 \\
\hline Paper & .56 & .10 & .68 & .13 & .63 & .08 & .19 & .03 & .04 & .04 & .13 & .14 \\
\hline Printing & .99 & .18 & 1.00 & .03 & .85 & .02 & .37 & .07 & .66 & .03 & .77 & .05 \\
\hline Chemicals & .70 & .09 & .88 & .04 & .75 & .04 & -.09 & .13 & .75 & .02 & 1.03 & .04 \\
\hline Petroleum & .90 & .09 & .95 & .04 & .69 & .06 & .54 & .05 & .63 & .06 & .60 & .05 \\
\hline Rubber & .54 & .09 & .71 & .08 & .67 & .10 & -.05 & .08 & .37 & .04 & 1.08 & .14 \\
\hline Leather & .91 & .19 & .98 & .03 & .86 & .03 & .15 & .09 & .51 & .04 & .86 & .09 \\
\hline Stone,Clay,Glass & .39 & .10 & .75 & .05 & .83 & .06 & -.24 & .06 & .47 & .03 & 1.27 & .06 \\
\hline Primary Metal & .42 & .13 & .49 & .10 & .57 & .13 & .04 & .05 & .29 & .05 & .91 & .12 \\
\hline Fab Metal & .18 & .15 & .86 & .03 & .97 & .04 & -1.22 & .20 & .76 & .02 & 1.21 & .02 \\
\hline Machinery & .29 & .10 & .82 & .04 & .92 & .03 & -1.18 & .11 & .82 & .01 & 1.14 & .02 \\
\hline Elec Machinery & .41 & .11 & .77 & .06 & .83 & .03 & -.87 & .11 & .74 & .03 & 1.20 & .04 \\
\hline Trans Equip & -.13 & .09 & .58 & .08 & 1.09 & .06 & -.58 & .06 & .50 & .03 & 1.60 & .07 \\
\hline Instruments & .19 & .21 & .94 & .02 & .99 & .02 & -1.33 & .21 & .86 & .01 & 1.10 & .01 \\
\hline Other & .83 & .18 & .97 & .03 & .87 & .04 & -.46 & .12 & .69 & .02 & 1.17 & .03 \\
\hline Non-Durables & .35 & .07 & .71 & .08 & .82 & .06 & -.19 & .05 & .31 & .03 & 1.54 & .11 \\
\hline Durables & -.03 & .08 & .62 & .05 & 1.02 & .05 & -1.24 & .09 & .64 & .02 & 1.45 & .05 \\
\hline Total & .09 & .09 & .59 & .06 & .94 & .07 & -.78 & .07 & .53 & .02 & 1.62 & .06 \\
\hline
\end{tabular}

\section{Notes:}

1. The sample period is $1967: 5-1984: 12$.

2. The statistics in the table are computed for monthly logarithmic growth rates.

3. The $\mathrm{Y}_{4}$ results are based on the finished goods only definition of output.

4. $\lambda^{I P}$ is the weight on IP in an optimal forecast of the true series. We estimate $\lambda^{I P}=$ $\operatorname{Cov}\left(\Delta y^{Y 4}, \Delta y^{Y 4}-\Delta y^{I P}\right) / \operatorname{Var}\left(\Delta y^{Y 4}-\Delta y^{I P}\right)$. Under the assumption that $\operatorname{Var}\left(\Delta u^{Y 4}\right)=$ $\operatorname{Var}\left(\Delta u^{I P}\right)=0, \lambda^{I P}=\operatorname{Var}\left(\Delta e^{Y 4}\right) /\left(\operatorname{Var}\left(\Delta e^{Y 4}\right)+\operatorname{Var}\left(\Delta e^{I P}\right)\right)$.

5. $\kappa^{I P}$ is the fraction of the variation in $I P$ due to measurement error. We estimate $\kappa^{I P}=$ $1-\operatorname{Cov}\left(\Delta y^{I P}, \Delta y^{Y 4}\right) / \operatorname{Var}\left(\Delta y^{I P}\right)$. Under the assumption that $\operatorname{Var}\left(\Delta u^{Y 4}\right)=\operatorname{Var}\left(\Delta u^{I P}\right)=0$, $\kappa^{I P}=\operatorname{Var}\left(\Delta e^{I P}\right) /\left(\operatorname{Var}\left(\Delta y^{I P}\right) . \kappa^{Y \mathbf{4}}\right.$ is defined similarly. 


\begin{tabular}{|l|r|r|r|r|r|r|r|r|}
\hline \multicolumn{7}{|c|}{ Table A5: Estimates of "u-type" Measurement Errors } \\
\hline & \multicolumn{3}{|c|}{ Seasonally Adjusted } & \multicolumn{3}{|c|}{ Seasonally Unadjusted } \\
\hline & $\hat{\kappa}_{I P}$ & $\hat{\kappa}_{Y \perp}$ & $\hat{\lambda}_{I P}$ & \multicolumn{1}{|c|}{ se } & $\hat{\kappa}_{I P}$ & $\hat{\kappa}_{Y}$ & $\hat{\lambda}_{I P}$ & se \\
\hline Food & .82 & .12 & .12 & .03 & .55 & -.04 & -.08 & .07 \\
Tobacco & .73 & .17 & .19 & .07 & .25 & .42 & .63 & .11 \\
Textiles & .65 & .21 & .24 & .10 & .41 & -.11 & -.35 & .09 \\
Apparel & .80 & .18 & .19 & .05 & .61 & -.04 & -.07 & .04 \\
Lumber & .70 & .14 & .16 & .05 & .54 & -.05 & -.09 & .06 \\
Furniture & .82 & .11 & .12 & .03 & .68 & -.16 & -.30 & .05 \\
Paper & .49 & .29 & .37 & .08 & .03 & .18 & .87 & .14 \\
Printing & .85 & .15 & .15 & .02 & .55 & .17 & .23 & .05 \\
Chemicals & .68 & .22 & .25 & .04 & .77 & -.02 & -.03 & .04 \\
Petroleum & .67 & .30 & .31 & .06 & .44 & .30 & .40 & .05 \\
Rubber & .53 & .26 & .33 & .10 & .38 & -.03 & -.08 & .14 \\
Leather & .85 & .14 & .14 & .03 & .47 & .08 & .14 & .09 \\
Stone,Clay,Glass & .65 & .14 & .17 & .06 & .53 & -.11 & -.27 & .06 \\
Primary Metals & .35 & .27 & .43 & .13 & .28 & .03 & .09 & .12 \\
Fab. Metals & .83 & .03 & .04 & .04 & .88 & -.15 & -.21 & .02 \\
Machinery & .76 & .07 & .08 & .03 & .91 & -.11 & -.14 & .02 \\
Elec Machinery & .66 & .14 & .17 & .03 & .84 & -.14 & -.20 & .04 \\
Trans Equip & .61 & -.05 & -.09 & .06 & .61 & -.23 & -.60 & .07 \\
Instruments & .92 & .01 & .02 & .02 & .94 & -.09 & -.10 & .01 \\
Other & .85 & .13 & .13 & .04 & .76 & -.11 & -.17 & .03 \\
Non-Durables & .61 & .14 & .18 & .06 & .35 & -.12 & -.54 & .11 \\
Durables & .62 & -.01 & -.02 & .05 & .80 & -.25 & -.45 & .05 \\
Total & .57 & .04 & .06 & .07 & .67 & -.26 & -.62 & .06 \\
\hline
\end{tabular}

Notes:

1. The sample period is $1967: 5-1984: 12$.

2. The statistics in the table are computed for monthly logarithmic growth rates.

3. The Y4 results are based on the finished goods only definition of output.

4. $\lambda^{I P}$ is the weight on IP in an optimal forecast of the true series. We estimate $\lambda^{I P}=1-$ $\operatorname{Cov}\left(\Delta y^{Y^{4}}, \Delta y^{Y^{4}}-\Delta y^{I P}\right) / \operatorname{Var}\left(\Delta y^{Y 4}-\Delta y^{I P}\right)$. Under the assumption that $\operatorname{Var}\left(\Delta e^{Y^{4}}\right)=$ $\operatorname{Var}\left(\Delta e^{I P}\right)=0, \lambda^{I P}=\operatorname{Var}\left(\Delta u^{Y 4}\right) /\left(\operatorname{Var}\left(\Delta u^{Y 4}\right)+\operatorname{Var}\left(\Delta u^{I P}\right)\right)$.

5. $\kappa^{I P}$ is the fraction of the variation in $I P$ due to measurement error. We estimate $\kappa^{I P}=$ $1-\operatorname{Var}\left(\Delta y^{I P}\right) /\left(\operatorname{Var}\left(\Delta y^{I P}\right)+\operatorname{Var}\left(\Delta y^{Y^{4}}\right)-\operatorname{Cov}\left(\Delta y^{I P}, \Delta y^{Y 4}\right)\right)$. Under the assumption that $\operatorname{Var}\left(\Delta e^{Y^{4}}\right)=\operatorname{Var}\left(\Delta e^{I P}\right)=0, \kappa^{I P}=\operatorname{Var}\left(\Delta u^{I P}\right) /\left(\operatorname{Var}\left(\Delta y^{*}\right) . \kappa^{Y 4}\right.$ is defined similarly. 
APPENDIX B

ADDITIONAL TABLES AND FIGURES

\begin{tabular}{|l|c|c|c|c|c|c|c|}
\hline \multicolumn{7}{|c|}{ Table B1: Seasonality of Prices } \\
\hline & $\chi^{2}$ & Signif. & Std.Dev. of & Std.Dev. of & Ratio & Std.Dev. of & Ratio \\
& Stat. & Level & Seasonals,P & Seasonals,IP & IP/P & Seasonals, Y4 & Y4/P \\
\hline Food & 37.9 & .000 & .004 & .029 & 7.4 & .040 & 10.3 \\
Tobacco & 43.9 & .000 & .003 & .134 & 42.2 & .095 & 29.7 \\
Textiles & 20.7 & .037 & .001 & .079 & 69.5 & .103 & 91.0 \\
Apparel & 93.9 & .000 & .002 & .061 & 30.2 & .107 & 52.8 \\
Lumber & 57.2 & .000 & .008 & .046 & 5.6 & .066 & 8.0 \\
Furniture & 38.6 & .000 & .002 & .054 & 35.9 & .095 & 63.2 \\
Paper & 47.1 & .000 & .003 & .059 & 22.4 & .053 & 20.2 \\
Printing & - & - & - & .035 & - & .034 & - \\
Chemicals & 27.4 & .004 & .003 & .021 & 8.3 & .049 & 19.1 \\
Petroleum & 26.8 & .005 & .003 & .023 & 7.1 & .016 & 5.1 \\
Rubber & 29.4 & .002 & .002 & .054 & 31.0 & .071 & 40.6 \\
Leather & 61.4 & .000 & .004 & .076 & 17.8 & .076 & 17.8 \\
Stone,Clay,Glass & 62.2 & .000 & .004 & .037 & 8.6 & .055 & 12.8 \\
Primary Metal & 73.7 & .000 & .003 & .049 & 15.8 & .054 & 17.5 \\
Fab Metal & 68.7 & .000 & .003 & .022 & 8.0 & .081 & 29.9 \\
Machinery & 37.3 & .000 & .001 & .024 & 23.2 & .085 & 82.6 \\
Elec Machinery & 38.1 & .000 & .001 & .026 & 25.4 & .080 & 76.9 \\
Trans Equip & 88.0 & .000 & .009 & .056 & 6.1 & .100 & 10.9 \\
Instruments & - & - & - & .015 & - & .076 & - \\
Other & - & - & - & .042 & - & .082 & - \\
Non-Durables & - & - & - & .034 & - & .043 & - \\
Durables & - & - & - & .028 & - & .072 & - \\
Total & - & - & - & .029 & - & .057 & - \\
\hline
\end{tabular}

Notes:

1. The sample period is 1967:5-1984:12, except for the price series for Transportation, for which it is 1969:2-1984:12.

2. The ratios reported are for the standard devation of the seasonals in IP or Y4 over the standard deviation of the seasonals in prices. 


\begin{tabular}{|c|c|c|c|c|c|c|c|c|}
\hline \multicolumn{9}{|c|}{ Table B2: Dickey-Fuller Tests on Production Series } \\
\hline & \multicolumn{4}{|c|}{ Finished Goods Only } & \multicolumn{4}{|c|}{ Finished Goods plus WIP } \\
\hline$\therefore$ & \multicolumn{2}{|c|}{$\begin{array}{l}\text { Seasonally } \\
\text { Adjusted }\end{array}$} & \multicolumn{2}{|c|}{$\begin{array}{l}\text { Seasonally } \\
\text { Unadjusted }\end{array}$} & \multicolumn{2}{|c|}{$\begin{array}{c}\text { Seasonally } \\
\text { Adjusted }\end{array}$} & \multicolumn{2}{|c|}{$\begin{array}{l}\text { Seasonally } \\
\text { Unadjusted }\end{array}$} \\
\hline & IP & Y4 & IP & $\mathrm{Y4}$ & IP & Y4 & IP & Y4 \\
\hline Food & -2.32 & -2.54 & -2.36 & -2.42 & -2.32 & -2.44 & -2.36 & -2.37 \\
\hline Tobacco & -2.38 & .1 .71 & -1.62 & -1.56 & -2.38 & -1.83 & -1.62 & -1.38 \\
\hline Textiles & -3.06 & -2.19 & -3.05 & -2.10 & -3.06 & -2.31 & -3.05 & -2.17 \\
\hline Apparel & -2.91 & -2.84 & -2.64 & -2.86 & .2 .91 & -3.00 & -2.64 & -2.96 \\
\hline Lumber & -2.87 & -2.67 & -3.01 & -2.69 & -2.87 & -2.66 & -3.01 & -2.58 \\
\hline Furniture & -3.63 & -2.76 & -3.70 & -2.58 & -3.63 & -2.88 & -3.70 & -2.60 \\
\hline Paper & -3.50 & -3.54 & -3.49 & -3.78 & -3.50 & -3.57 & -3.49 & -3.78 \\
\hline Printing & -1.71 & -2.64 & -1.81 & -2.36 & -1.71 & -2.58 & -1.81 & -2.28 \\
\hline Chemicals & -2.39 & -2.97 & -2.43 & -2.91 & -2.39 & -2.98 & -2.43 & -2.83 \\
\hline Petroleum & -1.16 & -1.93 & -1.06 & -1.84 & -1.16 & -1.97 & -1.06 & -1.84 \\
\hline Rubber & -2.86 & -2.81 & -2.76 & -2.59 & -2.86 & -2.85 & -2.76 & -2.62 \\
\hline Leather & -3.44 & -1.51 & -3.50 & -1.56 & -3.44 & -1.41 & -3.50 & -1.41 \\
\hline Stone,Clay,Glass & -3.25 & -2.37 & -3.32 & -2.36 & -3.25 & -2.45 & -3.32 & -2.36 \\
\hline Primary Metal & -2.84 & -3.02 & -2.75 & -2.87 & -2.84 & -2.96 & -2.75 & -3.00 \\
\hline Fab Metal & -3.34 & -2.48 & -3.19 & -2.65 & -3.34 & -2.91 & -3.19 & -2.81 \\
\hline Machinery & -3.57 & -3.14 & -4.37 & -3.29 & -3.57 & -3.53 & -4.37 & -3.64 \\
\hline Elec Machinery & -3.37 & -2.55 & -3.57 & -2.71 & -3.37 & -2.95 & -3.57 & -2.82 \\
\hline Trans Equip & -2.97 & -3.15 & -3.04 & -3.16 & -2.97 & -3.43 & -3.04 & -3.34 \\
\hline Instruments & -2.56 & -2.12 & -2.63 & -2.00 & -2.56 & -2.10 & -2.63 & -1.98 \\
\hline Other & -2.79 & -3.53 & -2.82 & -3.28 & -2.79 & -3.68 & -2.82 & -3.26 \\
\hline Non-Durables & .3 .26 & -2.43 & -3.50 & -2.45 & -3.26 & -2.42 & -3.50 & -2.46 \\
\hline Durables & -3.71 & -3.91 & -4.12 & -4.05 & -3.71 & -4.47 & -4.12 & -4.35 \\
\hline Total & -3.57 & -3.58 & -4.06 & -3.72 & -3.57 & -3.87 & -4.06 & -3.89 \\
\hline
\end{tabular}

Notes:

1. The sample period is $1968: 3-1984: 12$.

2. The entries in the table are the t-statistics on the lagged log level of output from a regression of the $\log$ growth rate on a constant, a time trend, the lagged log level of the series, and lags one through twelve of the $\log$ growth rate of the series. A value of -3.43 is required to reject the null at the $95 \%$ level.

3. The Y4 results in columns 2 and 4 are based on the finished goods only definition of output. The $\mathrm{Y} 4$ results in columns 6 and 8 are based on the finished goods plus work-in-progess definition of output. 


\begin{tabular}{|c|c|c|c|c|c|c|c|}
\hline \multicolumn{8}{|c|}{$\begin{array}{c}\text { Table B3a: Summary Statistics, Seasonally Adjusted Data } \\
\text { Quarterly averages of monthly data }\end{array}$} \\
\hline & \multicolumn{2}{|c|}{ Mean } & \multicolumn{2}{|c|}{ Standard Dev. } & \multicolumn{2}{|c|}{ Autocorrelation } & \multirow{2}{*}{$\begin{array}{l}\text { Cross } \\
\text { Correl. }\end{array}$} \\
\hline & IP & $\mathrm{Y4}$ & IP & $\mathrm{Y4}$ & IP & Y4 & \\
\hline Food & .0079 & .0045 & .010 & .021 & -.03 & -.07 & .49 \\
\hline Tobacco & .0018 & -.0016 & .031 & .061 & -.38 & -.51 & .46 \\
\hline Textile & .0048 & .0043 & .042 & .031 & .42 & .32 & .59 \\
\hline Apparel & .0033 & .0031 & .032 & .049 & .36 & .08 & .52 \\
\hline Lumber & .0046 & .0070 & .045 & .056 & .24 & .02 & .71 \\
\hline Furniture & .0092 & .0094 & .034 & .043 & .47 & .31 & .70 \\
\hline Paper & .0084 & .0066 & .031 & .026 & .35 & .29 & .76 \\
\hline Printing & .0094 & .0061 & .017 & .023 & .52 & .04 & .41 \\
\hline Chemicals & .0124 & .0091 & .026 & .029 & .51 & .34 & .74 \\
\hline Petroleum & .0026 & .0051 & .028 & .031 & -.10 & .11 & .57 \\
\hline Rubber & .0161 & .0069 & .045 & .050 & .31 & .01 & .72 \\
\hline Leather & -.0090 & -.0095 & .036 & .061 & .15 & -.03 & .58 \\
\hline Stone,Clay,Glass & .0061 & .0026 & .031 & .037 & .42 & .13 & .79 \\
\hline Primary Metal & -.0018 & -.0013 & .073 & .068 & .20 & .23 & .87 \\
\hline Fab Metal & .0036 & .0030 & .030 & .047 & .63 & .09 & .61 \\
\hline Machinery & .0110 & .0099 & .031 & .038 & .70 & .50 & .77 \\
\hline Elec Machinery & .0151 & .0125 & .030 & .039 & .58 & .33 & .74 \\
\hline Trans Equip & .0051 & .0044 & .054 & .074 & .03 & -.07 & .87 \\
\hline Instruments & .0146 & .0116 & .019 & .043 & .56 & .06 & .49 \\
\hline Other & .0042 & .0043 & .026 & .055 & .43 & -.16 & .40 \\
\hline Non-Durables & .0086 & .0053 & .019 & .018 & .49 & .33 & .78 \\
\hline Durables & .0073 & .0063 & .030 & .036 & .50 & .29 & .91 \\
\hline Total & .0079 & .0059 & .024 & .026 & .54 & .32 & .90 \\
\hline
\end{tabular}

Notes:

1. The sample period is $1967: 4-1984: 4$.

2. The statistics in the table are computed for quarterly logarithmic growth rates.

3. The Y4 results are based on the finished goods plus work-in-progress definition of output. 


\begin{tabular}{|c|c|c|c|c|c|c|c|}
\hline \multicolumn{8}{|c|}{$\begin{array}{c}\text { Table B3b: Summary Statistics, Seasonally Adjusted Data } \\
\text { Annual data, Annual Average of monthly data }\end{array}$} \\
\hline & \multicolumn{2}{|c|}{ Mean } & \multicolumn{2}{|c|}{ Standard Dev. } & \multicolumn{2}{|c|}{ Autocorrelation } & \multirow{2}{*}{$\begin{array}{l}\text { Cross } \\
\text { Correl. }\end{array}$} \\
\hline & IP & $\mathrm{Y} 4$ & IP & Y4 & IP & $\mathrm{Y} 4$ & \\
\hline Food & .0312 & .0181 & .018 & .023 & .03 & -.53 & .53 \\
\hline Tobacco & .0059 &. .0078 & .033 & .041 & -.30 & .17 & .71 \\
\hline Textile & .0171 & .0184 & .066 & .062 & .02 & .11 & .93 \\
\hline Apparel & .0135 & .0134 & .070 & .056 & .04 & -.08 & .72 \\
\hline Lumber & .0182 & .0271 & .087 & .088 & .14 & .04 & .96 \\
\hline Furniture & .0361 & .0339 & .093 & .097 & .18 & .15 & .98 \\
\hline Paper & .0323 & .0246 & .062 & .060 & -.17 & -.22 & .95 \\
\hline Printing & .0381 & .0239 & .050 & .046 & .24 & .19 & .93 \\
\hline Chemicals & .0446 & .0345 & .064 & .065 & -.15 & -.04 & .97 \\
\hline Petroleum & .0100 & .0183 & .047 & .057 & .53 & -.09 & .44 \\
\hline Rubber & .0581 & .0226 & .097 & .099 & .02 & .15 & .90 \\
\hline Leather & -.0361 & -.0350 & .044 & .066 & -.29 & -.25 & .74 \\
\hline Stone,Clay,Glass & .0231 & .0078 & .082 & .079 & .12 & .16 & .98 \\
\hline Primary Metal & -.0086 & -.0063 & .144 & .133 & -.23 & -.18 & .98 \\
\hline Fab Metal & .0105 & .0041 & .090 & .086 & .07 & .12 & .98 \\
\hline Machinery & .0447 & .0404 & .096 & .104 & .07 & .06 & 1.00 \\
\hline Elec Machinery & .0581 & .0489 & .089 & .092 & .17 & .15 & .98 \\
\hline Trans Equip & .0144 & .0118 & .101 & .131 & .05 & .06 & .98 \\
\hline Instruments & .0552 & .0493 & .055 & .066 & .17 & .09 & .97 \\
\hline Other & .0153 & .0181 & .068 & .080 & .01 & -.01 & .96 \\
\hline Non-Durables & .0327 & .0207 & .046 & .038 & .01 & -.05 & .96 \\
\hline Durables & .0269 & .0224 & .083 & .091 & .07 & .08 & .99 \\
\hline Total & .0293 & .0217 & .067 & .065 & .05 & .06 & .99 \\
\hline
\end{tabular}

Notes:

1. The sample period is $1969-1984$.

2. The statistics in the table are computed for annual logarithmic growth rates.

3. The Y4 results are based on the finished goods plus work-in-progress definition of output. 


\begin{tabular}{|l|c|c|}
\hline \multicolumn{2}{|c|}{ Table B4: Variance of Production over Variance of Sales, } \\
Seasonally Adjusted Data
\end{tabular}

Notes:

1. The sample period is $1967: 5-1984: 12$.

2. The statistics in the tables are computed for deviations from exponential trend; see text for details.

3. The Y4 results are based on the finished goods plus work-in-progress definition of output. 


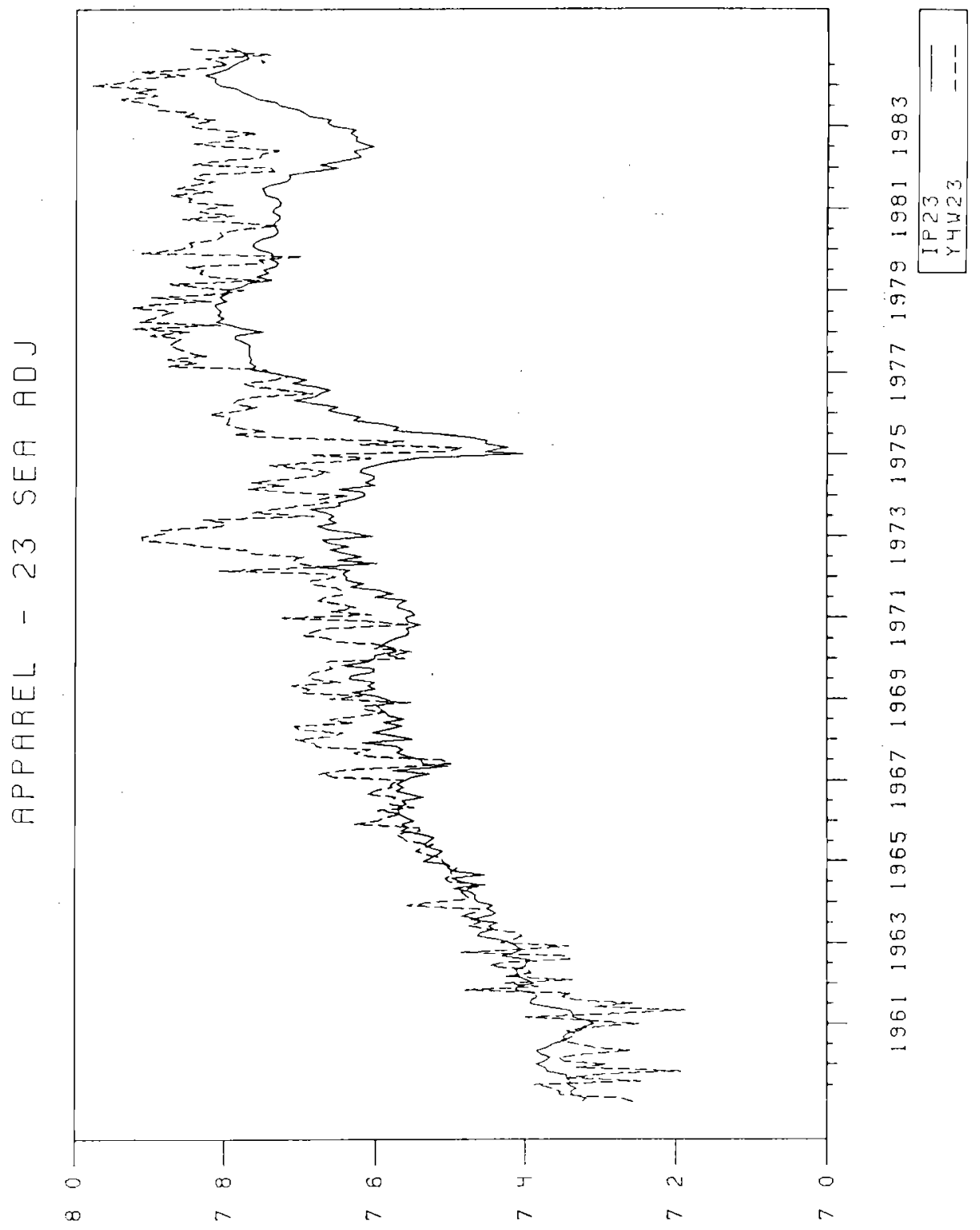




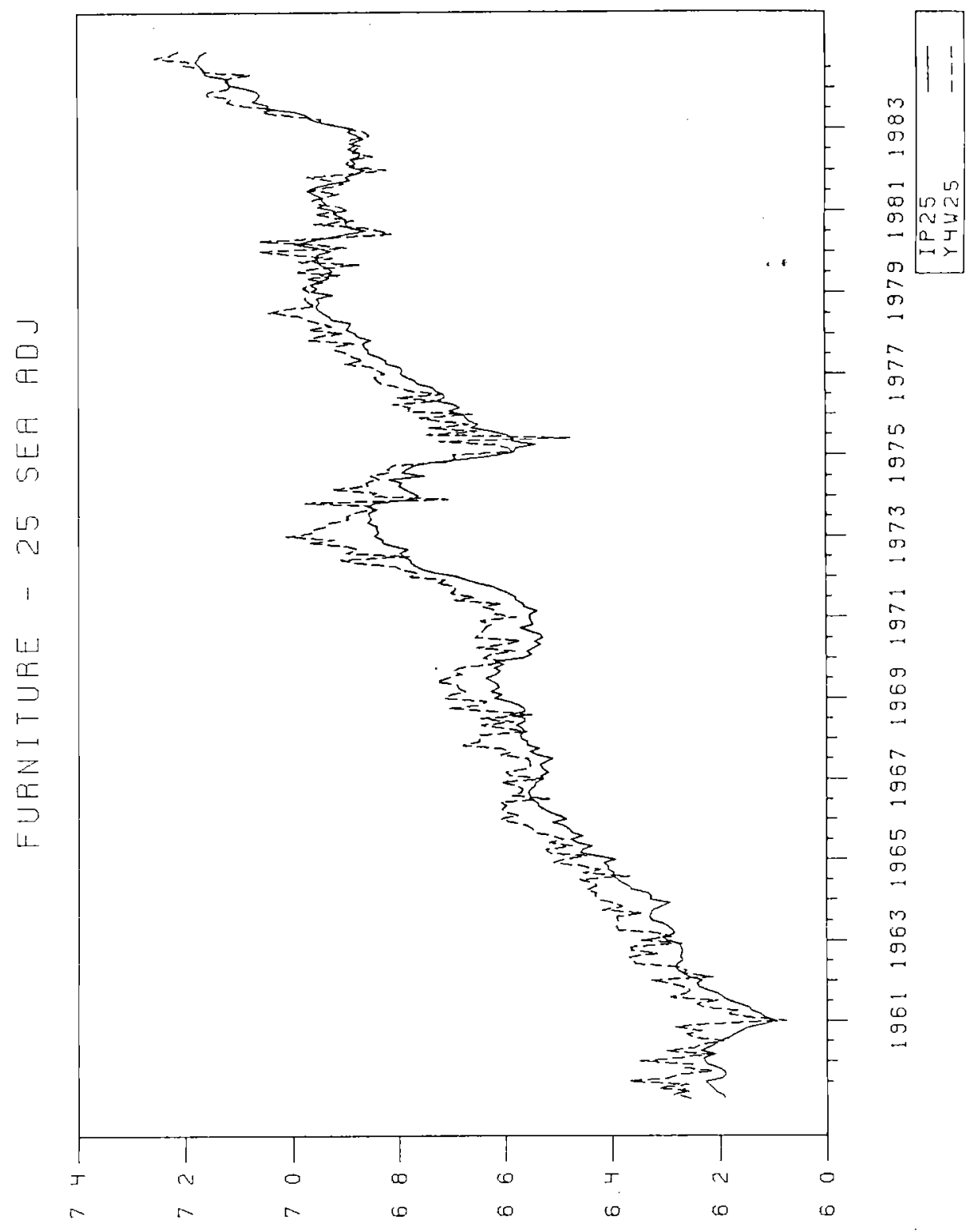




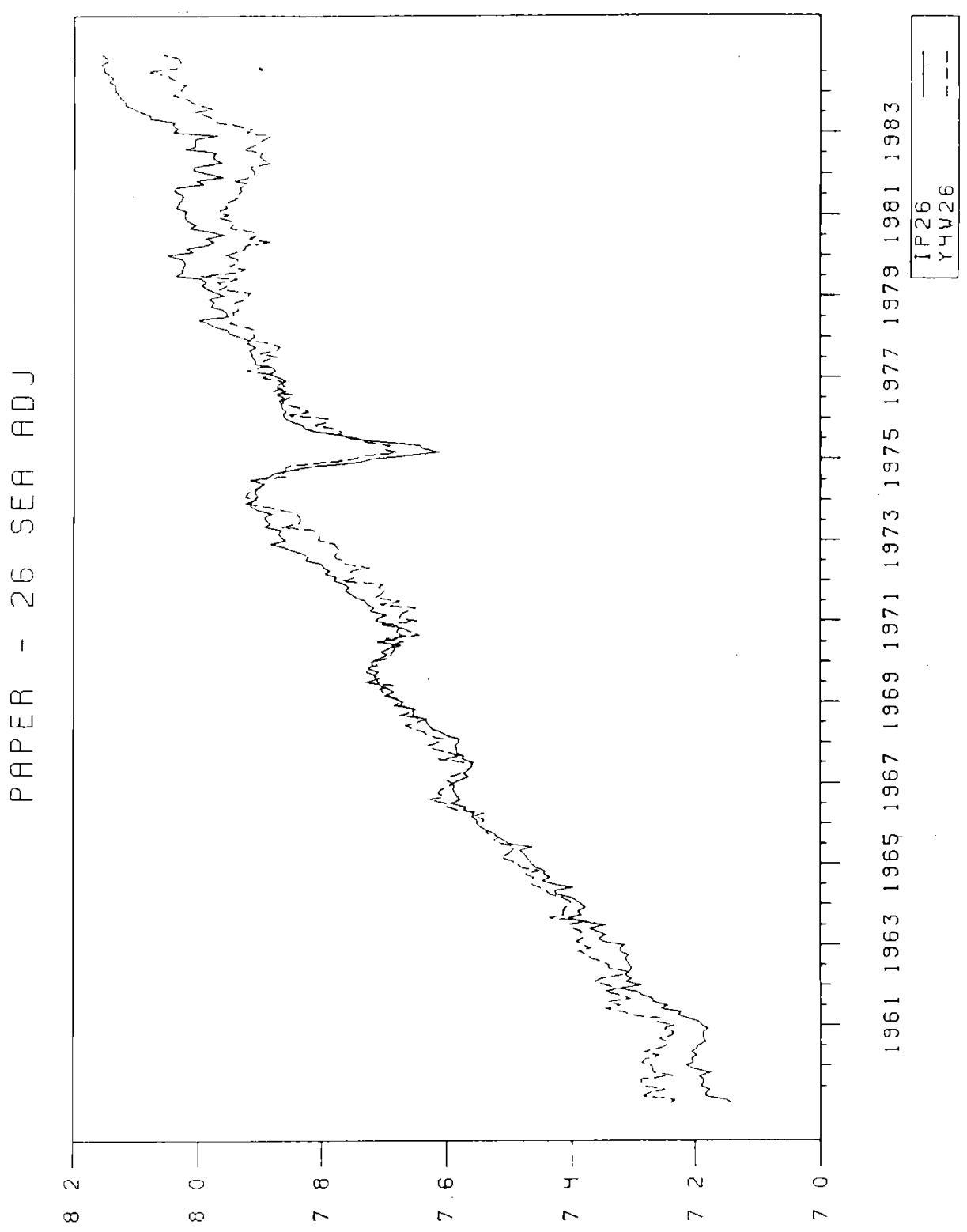




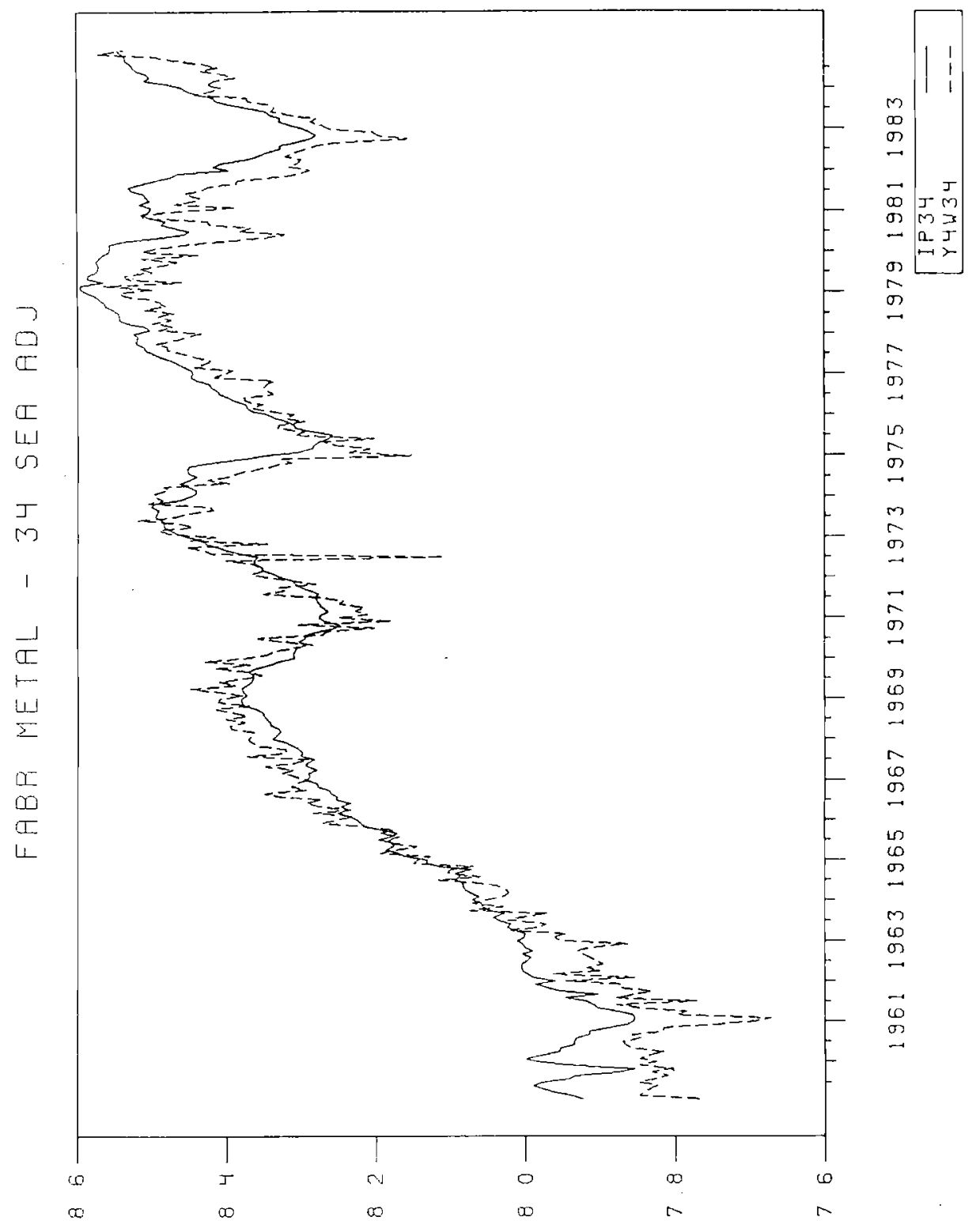




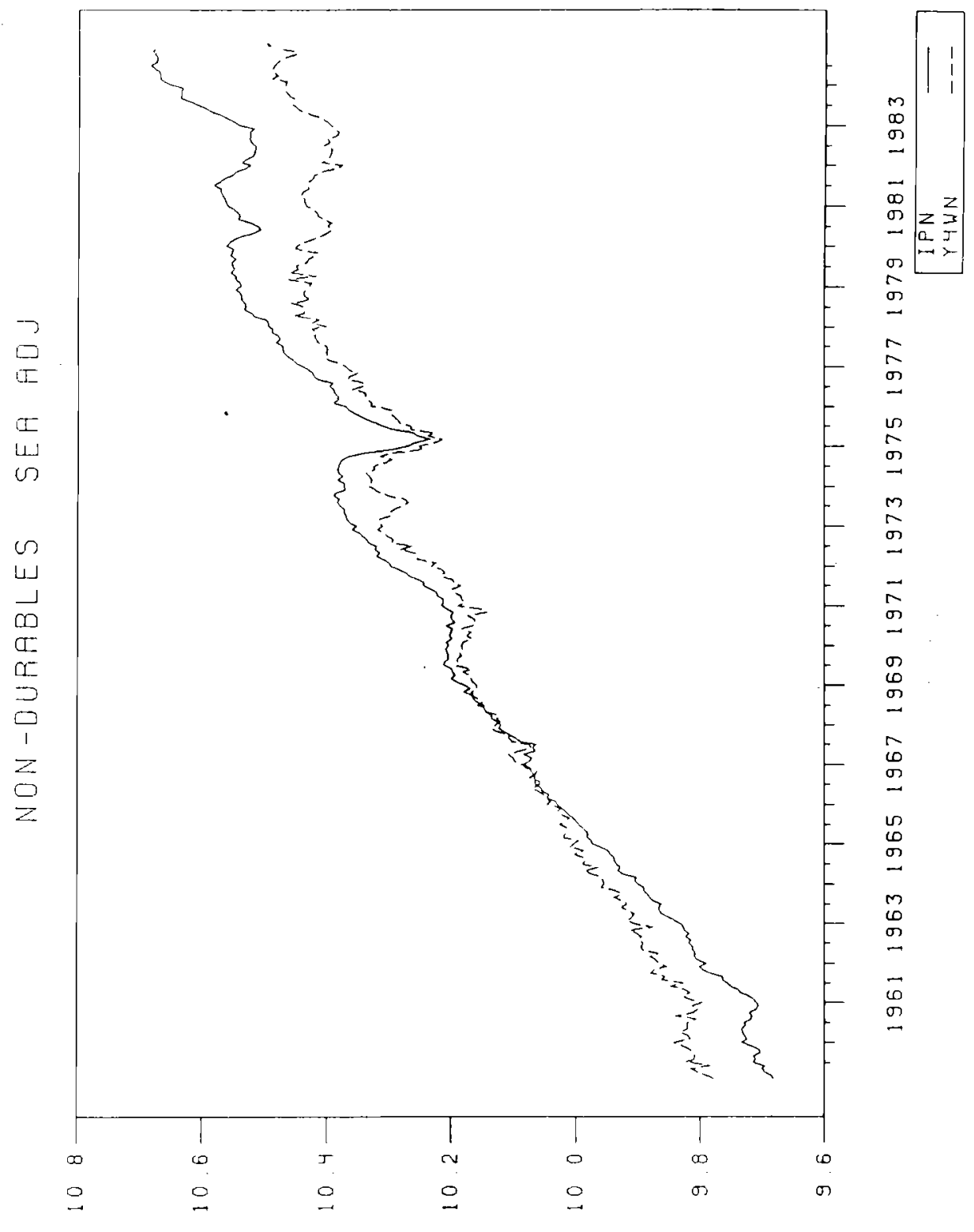




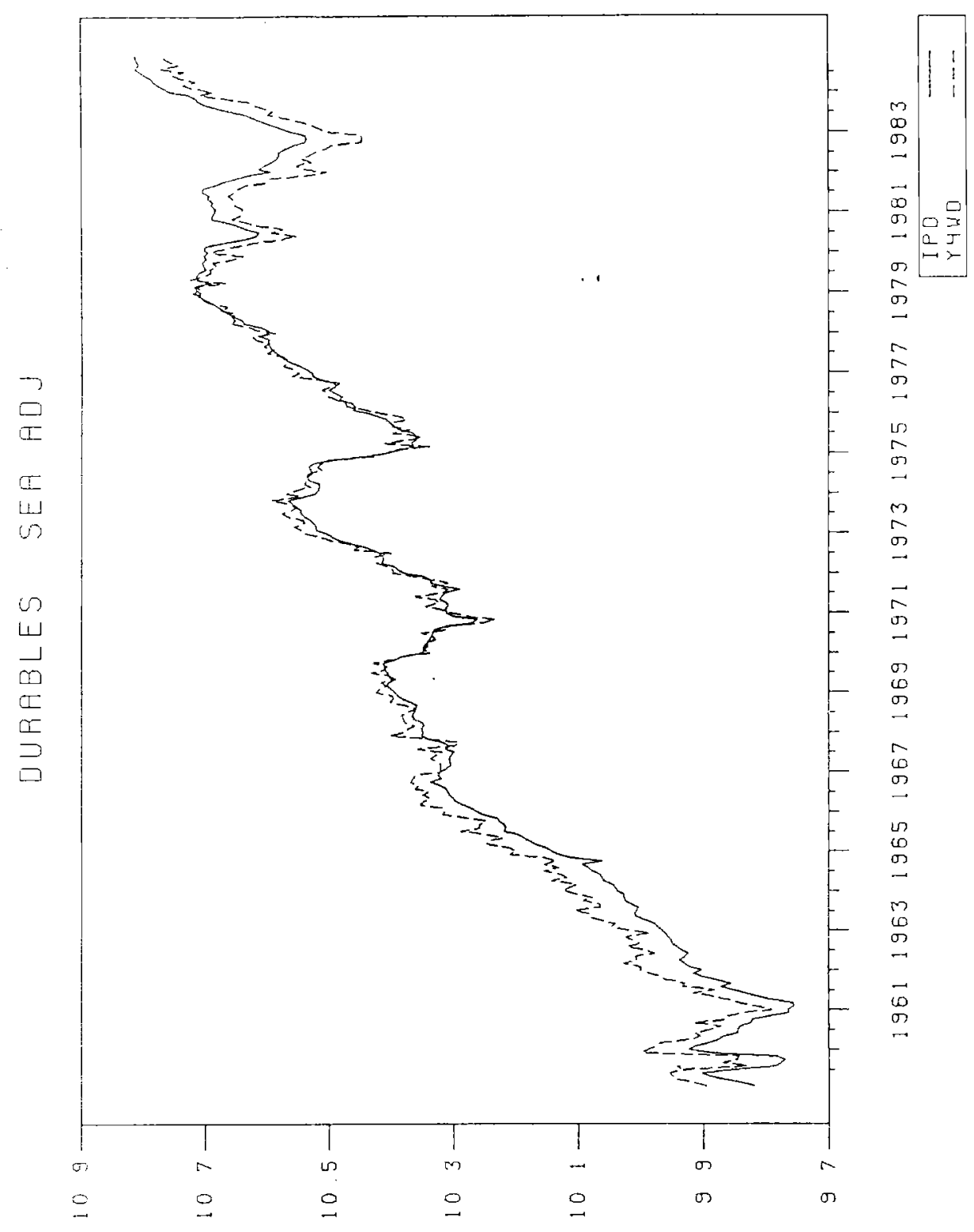

